Revista internacional

de Historia

de la Comunicación

\title{
CARICATURISTAS Y REVISTAS SATÍRICAS EN LA SEVILLA DEL SIGLO XIX
}

\section{Caricaturists and satirical publications in the 19th-century Seville}

DOI: http://dx.doi.org/10.12795/RiHC.2017.i09.01

Jesús Carlos Méndez Paguillo

Universidad de Sevilla

jcarlosmendez@hotmail.es

Recibido: 4-10-2017

Aceptado: 17-11-2017

Resumen: En este estudio pretendemos realizar una recopilación de las publicaciones satíricas y festivas sevillanas del siglo XIX que contenían ilustraciones, tanto viñetas como caricaturas y que, o bien se encuentran citadas en las obras bibliográficas locales, o bien se hallan físicamente en las hemerotecas, archivos y otras instituciones académicas.

Además, aportamos algunos comentarios y apuntes sobre las más importantes, como: El Tío Clarín, El Loro, La Giralda, El Padre Adam, La Zurra, El Alabardero, Perecito, Sevilla Cómica, El Buen Humor, Sevilla en Broma y algunas más, junto a los nombres de los dibujantes más destacados, como: Luis Mariani, Teodoro Aramburu, José Chaves, Blas, Juan Moreno (Grafito), Tomás Povedano y Fernando Tirado, entre otros. 
Palabras clave: Revistas satíricas, revistas festivas, caricaturistas, humoristas gráficos, Sevilla siglo XIX

\begin{abstract}
In this study we intend to compile satirical and festive publications of typical spanish to the 19th century. These comprised illustrations, cartoons and caricatures, which were referenced in local literature or were physically found in newspaper archives, files or another academic institution.

In addition, we have provided comments and notes of the most important ones, such as: El Tío Clarín, El Loro, La Giralda, El Padre Adam, La Zurra, El Alabardero, Perecito, Sevilla Cómica, El Buen Humor, Sevilla en Broma, and others. Along with the names of the most prominent artists, like: Luis Mariani, Teodoro Aramburu, José Chaves, Blas, Juan Moreno (Grafito), Tomás Povedano y Fernando Tirado, and others.
\end{abstract}

Keywords: Satirical publications, holiday magazines, cartoonists, caricaturists, 19thcentury Seville

\title{
Introducción
}

El objetivo de este artículo es establecer una recopilación de las publicaciones satíricas que contenían caricaturas y viñetas, y que fueron editadas en Sevilla durante el siglo XIX. En este sentido, realizamos un análisis de algunas de estas revistas desde su prospecto y de las obras de los caricaturistas, todo ello en relación con su contexto histórico.

Para realizar este artículo nos hemos basado fundamentalmente en la obra de Manuel Chaves Rey: "Historia y Bibliografía de la prensa sevillana" de 1896, reeditado en 1995 ${ }^{1}$. Y complementado con las obras de: Manuel Aznar y Gómez, "El Periodismo en Sevilla", de 1889 y reeditado en 2009; con "Historia del Periodismo Andaluz" y "Censo de la prensa española del Sexenio Democrático 1868-1874", de Antonio Checa Godoy de 2011 y 2016 respectivamente; con la obra de Julia Sánchez López de 2015, "Catálogo de la Prensa Sevillana (1661-2014)"; con la "Guía de Sevilla y su provincia" de Gómez Zarzuela. También con la recopilación de Manuel Ferrand sobre revistas humorísticas de Sevilla, sus dibujantes y los temas que trataban, desde la sección "Sevilla en Broma" 2 (ABC Sevilla, desde el 24-10-1978 al 16-12-1978). Y, por supuesto, con su búsqueda y localización en la Hemeroteca de Sevilla, en la Biblioteca de la Universidad de Sevilla ${ }^{3}$ y el catálogo de la Hemeroteca Municipal de Madrid de

1 Una presentación y divulgación de la obra de Historia y Bibliografía de la Prensa sevillana de Manuel Chaves ya fue realizada por Alfonso Braojos, y publicada en el diario ABC Sevilla en 55 entregas, del 5 de mayo de 1981 hasta el 9 de julio de 1981.

${ }^{2}$ Con este mismo título ya existió en Sevilla en el año 1893 una revista festiva con magníficas caricaturas en la portada de Fernando Tirado, cuyos originales estaban realizados en óleo.

3 Agradecemos la colaboración de José Bernárdez Fonseca, por su trabajo de curso de doctorado del año 2002: Catálogo de periódicos y revistas impresos en los siglos XVIII y XIX. Biblioteca de la Facultad de Filología y Geografía e historia de la Universidad de Sevilla. 
Publicaciones Periódicas del siglo XIX. España. Andalucía (2001). Además del fondo digital de la Biblioteca Nacional de España.

\section{Las revistas satíricas sevillanas del XIX y sus dibujantes}

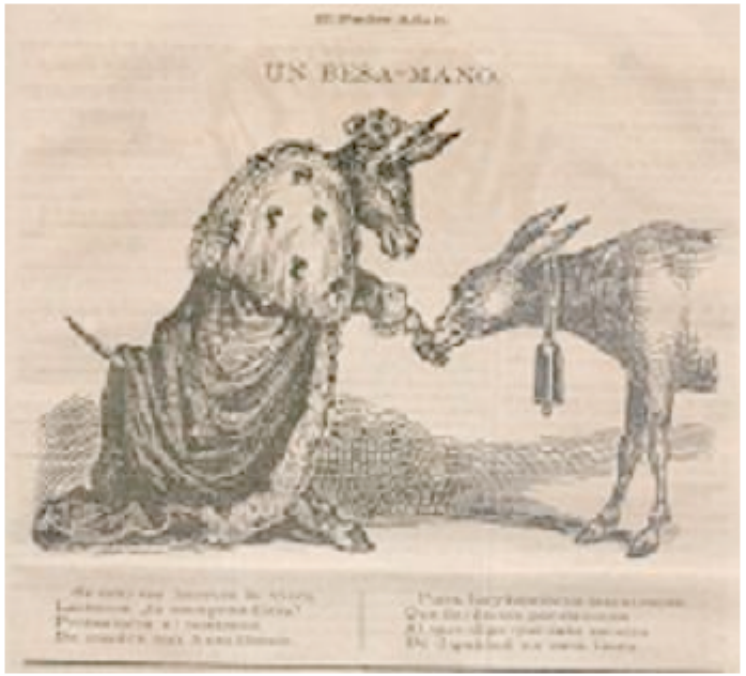

Imagen 1.- Viñeta de Luis Mariani en El Padre Adam n. ㅇ 44. Junio de 1869. La guerra mediática que existió tras la Gloriosa y el exilio de la reina Isabel II fue utilizada por los republicanos para desprestigiar a la monarquía. En la viñeta se representa a un rey y un súbdito transformados en burros. Título: Un Besa-Mano. Texto: Si esto un borrico lo viera/ Lectores. ¿Lo comprendiera?/ Protestaría al instante/ De cuadro tan humillante/ Pues hay hombres tan atroces/ Que darán un par de coces/ Al que diga que esta escena/ De dignidad no está llena.

Por lo general, durante el siglo XIX, las revistas satíricas tuvieron un gran éxito de difusión en las principales ciudades de Europa y de España. Sobre todo, a partir de la segunda mitad del siglo, gracias al auge de la burguesía y a la innovación en la técnica de la litografía (Bozal, 1989).

Estas publicaciones serán clasificadas en dos tipos; las joco-serias ${ }^{4}$, de opinión política, y las denominadas magazines, basadas en el entretenimiento, con noticias, artículos literarios, de costumbres, modas, variedades, etc., (Summa Artis, Vol. XXXII, p. 319). Aunque quizás, el mejor término que defina a estas segundas sea el de revistas festivas

\footnotetext{
4 Lo joco-serio es la crítica que mezcla lo jocoso con lo serio, según la fórmula de "reír para no llorar". Las primeras manifestaciones se encuentran en la crítica política e ideológica que se crea con la Guerra de la Independencia. Aunque también se abordan temas sociales, económicos, religiosos y culturales (Summa Artis, XXXII: 320). Bozal (1989: 96), lo define como un género propio del radicalismo burgués donde las posibilidades de intervenir en política son inanes o imposibles.
} 
por incluir entre sus páginas artículos y poesías de carácter festivo, cómico o burlón. Así, las revistas joco-serias se centrarán en poner el acento y la crítica, en muchos casos gruesa, sobre los conflictos políticos que sucedieron en la España del XIX, mientras que las festivas harán hincapié en otro tipo de sucesos, más sociales y culturales, como; críticas de teatros, espectáculos taurinos y de costumbres. No obstante, como afirma el profesor Checa Godoy (2016), muchos títulos llevan al engaño, pareciendo satíricos siendo literarios y viceversa, disfrazándose de literarios los políticos.

En España, muchas de las revistas joco-serias surgieron con una función de altavoz político y como medio de difusión de ciertas ideas y también, en respuesta a otras revistas, diarios o partidos, siendo una de las características la fuerte ideologización de ellas. Ejemplo serán las publicaciones que aparecen durante la invasión de Napoleón, la Constitución de 1812, y el Trienio Liberal, entre absolutistas defensores de la inquisición y la monarquía, contra franceses y liberales. Después, con Isabel II, entre liberales, conservadores, carlistas, republicanos y monárquicos, que se acentúa durante la Gloriosa y el Sexenio Revolucionario, cuando se produce la consolidación de las viñetas y caricaturas en la prensa satírica, llegando a contar en este trabajo de recopilación hasta 43 cabeceras sevillanas con ilustraciones desde el año 1846 hasta el final de siglo XIX. Siendo a partir de la Restauración Borbónica cuando más cabeceras humorísticas salieron a la calle, aunque, con un carácter más festivo que político (Gamonal, 1983). Entre otros motivos por que se estabiliza la vida gubernamental y se normaliza la edición de publicaciones con la Ley de Policía y de Imprenta de 1883.

Por último, según Meléndez Malavé (2007), el final de siglo va a suponer el comienzo de la transformación del modelo periodístico de opinión política por el de información con vocación empresarial, mostrándose como el canto de cisne de este género, lo que supondrá la desaparición de buena parte de las publicaciones satíricas ${ }^{5}$, a excepción de algunas cabeceras que lograrán permanecer hasta el primer cuarto de siglo XX, como fueron La Fusta y Don Cecilio de Triana en Sevilla. No obstante, muchos dibujantes finiseculares pasaron a desarrollar su obra en la prensa diaria ya entrado el siglo XX, (Rodríguez Aguilar, 2000: 23) y (Checa, 2011: 292), momentos en los que la caricatura española toma especial relevancia gracias a los Salones Humorísticos organizados por el crítico de arte José Francés.

Por todo ello este periodo es considerado como la "Edad de Oro" de la prensa satírica en España (Meléndez Malavé, 2007:63), o “El siglo de las caricaturas" (Bozal, 1989).

\footnotetext{
5 El profesor Checa Godoy (2011), nos lo cuenta también: “Entre 1875 y 1900 nacen en Sevilla en torno a los sesenta periódicos satíricos, de 1901 a 1923 son ya sólo poco más de una decena. Ninguno verá la luz durante la Dictadura de Primo de Rivera y cuatro nacen con la II República, todos ellos fugacísimos. Cuando llega la guerra, no hay ya prensa humorística en la ciudad, tras un siglo que aúnan el ingenio humorístico con la caricatura y la ilustración con frecuencia de excelente nivel".
} 
Las revistas satíricas destacaban por sus nombres; animales pequeños, molestos, parlantes; objetos ruidosos; referencias demoníacas u otros seres maliciosos; instrumentos para infligir castigos físicos; apodos; tipos populares y marginales y títulos réplica (Meléndez Malavé, 2007), que en muchas ocasiones están representadas por un dibujo alegórico en la cabecera de la portada, siendo el leit motiv de la publicación al descargar con alguno de los atributos del susodicho la crítica. Ejemplos serían los trompetazos de El Tío Clarín, los picotazos de El Loro, los zurriagazos de La Zurra, los repiques de La Campana, los alabardazos de El Alabardero, etc.

A principios de siglo los contenidos satíricos aparecen escritos en diálogos, epístolas, artículos y versos. Y a partir de bien entrada la segunda mitad del s. XIX, se le unen las viñetas y caricaturas, gracias a la litografía, que sustituía al grabado en madera (utilizado para estampas ${ }^{6}$ y libros). En Sevilla, el primer periódico de carácter chistoso del que tenemos constancia que incluía dibujos fue La Jovialidad ${ }^{7}$ en 1846 y de carácter satírico con caricaturas El Sacatrapo de 1860 (Chaves, 1995:334).

En cuanto a las viñetas e ilustraciones, en un principio eran un complemento del texto ${ }^{8}$, como ya aparece en la revista madrileña Fray Gerundio ${ }^{9}$ en 1837 , donde:

Ya aparecen ilustraciones, tópicas, convencionales y costumbristas que ocupan una página, sin una elaboración plástica joco-seria. Entre sus dibujantes estaban Batanero, Castelló, Jesús Avrial y Flores, A. Gómez y F. Miranda, (Summa Artis, XXXIII: 322 y 323 ).

6 A principios de siglo existían ilustraciones en hojas denominadas estampas (como las de Goya) y sirvieron como medio de difusión de los sucesos de la Guerra de la Independencia. Estas estampas antinapoleónicas, que comenzaron a ser difundidas en Europa por los ingleses en su lucha contra Francia, también se utilizaron en España para reflejar escenas de las batallas nacionales y contra José I, alias Pepe Botella; propagandísticas en un principio y, con un sentido crítico y satíricas después, durante el Trienio Liberal (Summa Artis, XXXII: 338).

7 Hemeroteca Municipal de Madrid. Publicaciones Periódicas del siglo XIX. España. Andalucía (2001), p. 199.

8 Además de ilustraciones como complemento a los textos, también se utilizaron para el diseño artístico-decorativo de las cabeceras de muchas revistas y en láminas como reclamo para atraer nuevos lectores. Como ejemplo, desde el año 1837 ya había en Sevilla periódicos como El Sevillano que regalaba folletos y álbumes de 'Vistas y de trajes de costumbres andaluzas' realizadas por Danzart, José Bécquer, Blanchart y Bejarano. También El Nuevo Paraíso en 1839, La Floresta Andaluza en 1843 y de 1844 El Para-Todos, El Genio de Andalucía, Museo Industrial Sevillano, La Bonanza y El Novelero. Todos ellos ya ofrecían grabados y una lámina litografiada a sus suscriptores (Ibíd: 1995).

9 El nombre de Fray Gerundio procede de una novela satírica famosa del siglo XVIII de José Francisco de Isla, denominada Historia del famoso predicador fray Gerundio de Campazas, alias Zotes. La revista obtuvo gran popularidad por sus 'Capilladas' satíricas sobre costumbres, problemas y personajes políticos, con los diálogos cómicos de Fray Gerundio y su lego Pelegrín Tirabeque. Sin embargo, no pudo reeditarse en Sevilla por la negativa del editor de la misma, D. Modesto Lafuente Zamalloa (Ibíd, 1995: 88). No obstante, sí se reeditaron aquí algunas 'Capilladas' y 'Disciplinazos' (números), entre 1838 y 1848, en panfletos u hojas sueltas, como: “El Sánalo-Todo", "Fuentes de leche y vino", "Que sea para bien”, “A quien le pican que no salten”, "Tirabeque con un trapo atrás”, (Sánchez, 2015: 182). 
Sin embargo, será la influencia de revistas europeas, entre ellas la francesa Le Charivari, (Barrero, M. 2010), las que marcan el estilo de publicación de prensa satírica ilustrada en España, siendo la revista madrileña Gil Blas (noviembre de 1864 hasta 1872), su mejor exponente:

Gil Blas consagró el modelo que, con algunos cambios sustanciales y un enriquecimiento técnico considerable, dominaría en la prensa satírica posterior. Desde el punto de vista gráfico y formal, dio una mayor importancia a la ilustración, al dibujo o caricatura, independizándola del texto, (Summa Artis, XXXII: 393-394).

Unos meses antes de aparecer Gil Blas, habían nacido en Andalucía las revistas El Cencerro (Córdoba, 1863) y El Tío Clarín (Sevilla, enero 1864). En ellas dibujarán los primeros caricaturistas españoles ${ }^{10}$, como Ortego en Madrid (Martín, 1979), (Llera Ruiz, 2003) o Luis Mariani en Sevilla (Ruiz Dávila, 2012).

En los dibujos, por un lado, se tratan satíricamente temas costumbristas de humor gratuito, los denominados popularmente como chistes; utilizando ambientes domésticos, de cortejos y engaños, modas, picaresca... Con los recursos predominantes del siglo anterior; Tipos o siluetas de personas, donde se esconde una exageración, deformación, transformación o semejanza con algún animal u objeto, y plasmándolas en el formato de aleluyas, historietas o viñetas lámina. Suelen llevar un título y un verso o breve diálogo a los pies, ya que hasta bien entrado el siglo XX aún no se había extendido el recurso de los globos o bocadillos de texto.

Por otro lado, las ilustraciones satíricas de temática política ${ }^{11}$ o crítica social, comenzarán a despuntar en los momentos previos a la revolución Gloriosa y tendrán su eclosión durante ésta, al permitirse mayor libertad de Imprenta ${ }^{12}$. Serán viñetas explicativas dado el alto índice de analfabetismo. En ellas suelen aparecer caricaturizados los protagonistas del suceso, utilizando metáforas visuales como alegorías y símbolos, dentro de escenarios que sirven para narrar una parodia cómica esperpéntica. Ejemplos serán las escenas de circo, teatro, carnaval, procesiones, etc.,

10 Además de Goya, precursor de este género, otros grandes dibujantes nacionales del XIX y principios del XX serán Alenza, Urrabieta, Eduardo Sojo, Cubas, Padró, Pellicer, Apeles Mestres, Perea, Julio Gros, Ángel Pons, Mecachis, Navarrete, Verdugo, Sancha, Antonio Villahermosa (Sileno), Moya, Apa, Tovar, Ricardo Marín, Fresno, Robledano, Miranda, Ricardo del Olmo, Xaudaró, Bagaría, Karikato, Márquez, Bartoluzzi... (Francés, 1915).

11 Desde finales del siglo XVIII hasta el XIX la caricatura y la ilustración españolas estaban sometidas a un condicionante que no existe en otros países: el pintoresquismo del dieciochesco, pasto del romanticismo más elemental (...) Sin embargo, desde mediados del siglo XIX la imagen de la España costumbrista irá cambiando hacia otros temas más actuales y nacionales, como son los hechos políticos que ocurren en la administración central y Europa, la política interior y sus vaivenes. (Bozal, 1989).

12 “La Gloriosa abre un periodo histórico para el periodismo en Andalucía. (...) Suprimidas de inmediato las fuertes fianzas previas y tantas limitaciones impuestas a la prensa en los últimos años del reinado de Isabel II, la prensa brota caudalosa, sobre todo la prensa republicana y federal". (Godoy, 2011: 149). 
para reflejar sarcásticamente la imagen del gobierno, de Isabel II y su familia, del clero y del país en general. Entre otros recursos abundarán las imágenes de una mujer representando a la Constitución, a la democracia, a la libertad... O las zooformas del burro o el simio para identificar la ignorancia e incultura (Imagen 1), o el león con el pueblo, entre otros. El profesor Bozal (1898: 94), lo interpreta describiéndolo con la idea de que los caricaturistas elaboraron un lenguaje en el que los políticos se mueven como marionetas haciendo cabriolas en un pequeño escenario representando una farsa, mientras, el resto de los mortales, nosotros los ciudadanos asistimos al espectáculo como espectadores.

Sobre las caricaturas en particular, también existirá un modelo a seguir como es el de los cabezones ${ }^{13}$ con cuerpos pequeñitos, muy bien reflejados en las obras del dibujante Ramón Cilla ${ }^{14}$, en la revista Madrid Cómico (1880), durante la Restauración Borbónica. Son ilustraciones detallistas con asimetrías acusadas donde los protagonistas son los personajes de la vida política y cultural del momento, representados en caricaturasretratos en las portadas, a modo de homenaje.

Sobre las viñetas tenemos que decir además, que muchas no llevaban nombre o iban firmadas con seudónimo ${ }^{15}$. No obstante, entre los dibujantes sevillanos que sobresalen en esta segunda mitad de siglo, coincidente con el Sexenio Revolucionario, estarán, como decíamos antes; Luis Mariani Jiménez (El Tío Clarín, 1864 y EL Padre Adam, 1868); el paisajista Joaquín Chichot y $\operatorname{Parody}^{16}$ (El Artista, 1850 y El Tío Clarín, 1864);

13 "El modelo de cabezones también fue utilizado por el británico Gill en la prensa del II Imperio. Es una gran cabeza sobre un cuerpo diminuto. Esta transposición o cambio de escala consigue el efecto cómico deseado y es el origen de su popularidad", (Gamonal, 2010:256).

14 Ramón Cilla (1859-1937), comenzó a dibujar con 14 años. Colaboró en El Cardo, El Mundo Cómico, La Filoxera, El Cencerro, La Broma, La Caricatura, La Carcajada, El Cesante, Blanco y Negro, y Madrid Cómico, que fue la que le dio más fama y en el que trabajó más de quince años consecutivos. Su prestigio le llevó a colaborar en catorce revistas simultáneamente (Casado Cimiano, 2006: 59). Además de los cabezones, puso de moda las figuras de los buscones y los cesantes (personal de confianza de la administración que abandonaba sus puestos con los cambios de gobiernos).

15 Los seudónimos se utilizaron para sortear la censura que imponían las leyes de Imprenta de cada gobierno, contribuyendo a que aumentara el ingenio de los autores. Unos de los seudónimos más conocidos y aún por identificar con total seguridad es el de SEM, firma que aparece en ilustraciones de la revista Gil Blas entre otras y en las estampas satírico-pornográficas de Los Borbones en pelota, donde se retrata a la familia real de Isabel II y su corte más próxima, y creadas durante el Sexenio revolucionario.

16 A pesar de no haber encontrado ninguna ilustración con su firma, sí sabemos que dibujó algunas de ellas por la recopilación de caricaturas y apuntes para los periódicos El Artista (1850) y El Tío Clarín (1864-1865), según nos cuenta su hijo Alejandro Guichot (1897).

Joaquín Guichot y Parody (Madrid, 1820-Sevilla, 1906). Dibujante, periodista, escritor, historiador y profesor. Al crearse en la capital andaluza la Escuela Superior de Ingenieros Industriales fue nombrado por R.O. de 1852, ayudante de dibujo lineal, topográfico y de proyectos de la misma, hasta que ganó por oposición la cátedra de la misma, y al suprimirse la mencionada Escuela, pasó a desempeñar dicha cátedra en un instituto de segunda enseñanza. Escribió innumerables obras de estudios sobre Sevilla, además de Historia de la Ciudad de Sevilla, Historia General de Andalucía, y un par de novelas. Es una persona importante en estos años dentro de la comunicación. Cuando llegó a Sevilla en 1846 muy 
Teodoro Aramburu Murua (EI Loro, 1867; El Alabardero, 1877 y El Renacimiento, 1884); José Chaves Ortiz (La Zurra, 1869). Y durante la Restauración Borbónica: Tomás Povedano (El Alabardero, 1877; La Ilustración Bética, 1881; El Renacimiento, 1884 y Perecito, 1887); Blas (El Alabardero, 1880-1885), Juan Moreno Suárez (alias Grafito y Frou-frou) en Perecito, 1887, El Cometa, 1888 y Sevilla Cómica, 1888, entre otras); I. González y J. Bermejo (que podría corresponderse con el seudónimo Fefeneque), también en Perecito y Sevilla Cómica; Fernando Tirado, Nicolás Pineda y Pinto, en Sevilla en Broma (1893); J. Moyano y G. Díaz Infante (Serio y Broma, 1894); Rafael Santa Ana, Luis Cáceres, Andrés Cánovas y J. Funes (Mari Clara, 1896). Todos ellos darán paso, ya entrado el siglo XX, a Manuel Alonso Moyano (Manolo), en Don Cecilio de Triana, y Andrés Martínez de León, con colaboraciones en prensa.

Otros dibujantes de Sevilla en periódicos y revistas locales de otras temáticas no satíricas fueron A. Rodríguez y J. B. Romero en El Nuevo Paraíso (1839); Manuel Barrera en El Genio de Andalucía (1844); Pedro Vega en el diario El Fígaro de 1881 y la revista taurina El Despeje de 1883; Alfonso Barrada y N. Tovar en La llustración Bética (1882); Juan García Ramos en El Renacimiento de 1884; Manuel Grima en El Burladero de Sevilla (1884); Juan Moyano en La Fiesta Nacional (1890); Y E. Garay en La Literaria Festiva de 1890, (Ibíd, 1995).

Por otro lado, dibujantes sevillanos que realizaron su obra en Madrid en el XIX, fueron Valeriano Bécquer y Pedro Rojas. Junto a los hermanos Luis y José Jiménez Aranda, Domingo Fernández González y Manuel García Rodríguez, en prensa seria ilustrada.

Desafortunadamente muchas de las cabeceras tuvieron una vida muy corta; un número, varios en unos meses y muy pocas superaron un año de existencia, entre otros motivos, por la censura, la escasa suscripción de lectores o sus contenidos de escasa calidad. Siendo las más duraderas El Alabardero, de noviembre de 1877 a mayo de 1878 y de enero de 1879 a 1885; la saga de El Tío Clarín, El Clarín, La Campana y Campanilla, con unos 7 años en la calle. Otras como El Padre Adam con 2 años; Perecito con 1 año; La Giralda y Sevilla Cómica con 6 meses; y El Loro, La Zurra, Buen Humor y Sevilla en Broma, con unos 4 meses.

En Sevilla, la mayoría de las publicaciones de este género salieron de las imprentas de Carlos Santigosa ${ }^{17}$, de Gironés y Orduña, de Hidalgo, o Moyano, entre otras. También

pronto destacó por sus colaboraciones en prensa. Como periodista trabajó en El Centinela de Andalucía (1843-1844), El Porvenir (1848-1909), La Andalucía (1858-1899), El Progreso (1883), fue director de El Eco Nacional (1870), Revista Hispano-Ultramarina (1872), La Asamblea (1874) Revista Sevillana (1872), El Ateneo (1874), La Religión y el Socialismo (1892) y colaboró en las revistas satíricas de El Galgo Negro y El Tío Clarín, (LAROUSSE).

${ }^{17}$ Carlos Santigosa y Gaspar (Barcelona, 1815-Sevilla, 1899), además de impresor fue editor de libros, como "Álbum sevillano" de litografías de la ciudad y de los periódicos de El Movimiento Continuo (1849), Adición a La Libertad (1855), Las Novedades de Sevilla (1864), El Tío Clarín (1864) y La Campana (1867- 
llama la atención el editor Isauro López de Ochoa, por la cantidad de títulos que dirigió $^{18}$, aunque sin fortuna. Éstas se vendían mediante suscripciones nominales desde la redacción, imprenta litográfica o librerías y también se voceaban en la calle.

Referente a las tiradas en Sevilla, El Tío Clarín en el n. 83 de 1865 aseguraba editar 10.000, al igual que El Alabardero en el n. $\cong 171$ de mayo de 1881. Datos interesantes si tenemos en cuenta los índices de analfabetismo en Sevilla; del 61,23\% para un censo de 118.298 habitantes en 1860; del 39,6\% en 1900 para una población de 148.315, (Braojos, Parias y Álvarez, 1990: 18-19 y 124).

\section{Los comienzos de las revistas satíricas y festivas con ilustraciones}

Además de La Jovialidad y El Sacatrapo, una de las revistas satíricas más representativas de este género que incluirá ilustraciones será El Tío Clarín (Imagen 2). Gran defensor de la revolución Gloriosa y de las ideas republicanas, según Checa Godoy (2011: 192): "El Tío Clarín ofrece un inequívoco talante federal y hace objeto de sus sátiras mucho más que a carlistas o alfonsinos a los partidos en el poder, esencialmente al progresista".

El Tío Clarín se autodefine como satírico, político, chismoso, entrometido y pendenciero. Comenzó el 4 de enero de 1864, hasta julio de 1865, volviendo en agosto de 1865 hasta diciembre de 1866. Se publicaba todos los lunes en números de 4 páginas con una gran viñeta litografiada. Por último, reaparece el 5 de diciembre de 1870 hasta el 24 de diciembre de 1871.

El dibujante será Luis Mariani ${ }^{19}$ (1840- ), (Imagen 3 y 4), y sus viñetas presentan un estilo personal de crítica social y moral, técnica que ya aplicaba en El Cencerro, mediante un dibujo premeditadamente tosco e ingenuo, (Summa Artis, XXXII: 404).

1868). Fue director de El Independiente (1846-1847), El Mediodía (1847-1848), La Campana (1867), EI Posibilista (1881-1895), y La Opinión en 1895.

${ }^{18}$ Además de las revistas satíricas: El Diablo (1871), El Capitán Centellas (1876), La Linterna (1880), El Duende (1880), La Panza, periódica conservadora (1884), y Juan Lanas (1885), Isauro López Ochoa colaboró en La Lucha (1883), periódico librepensador republicano y dirigió otras de distintas temáticas, como; El Kiosco Universal (1887) de anuncios; La Región Andaluza (1887) revista de Seguros y Ferrocarriles; El Propagandista (1889); La Mar de Infundios (1891), de variedades; El Compañero (1894), semanario republicano de las clases trabajadoras y El Popular (1896), de curiosidades, (ibíd, 1995).

19 Luis Mariani y Jiménez (Barrero, M: 2011): “Actuó como director, redactor, litógrafo y dibujante de: El Cencerro (Córdoba, 1863, cinco números), El Tío Clarín (186 números, de 1864 a 1867), El Clarín (diario continuación del anterior, 840 números publicados entre 1867 y 1870), La Campana (126 números entre 1867 y 1868 a diario), El Padre Adam (1 a 122, de 1868 a 1870), El Tío Clarín segunda época (52 números, de 1870 a 1871), y las publicaciones que editó entre las ciudades de Sevilla, Córdoba, Málaga y Madrid: El Cencerro segunda época (1869-1873, 230 números al menos) y El Tío Conejo (1875-1882, 401 números)". 

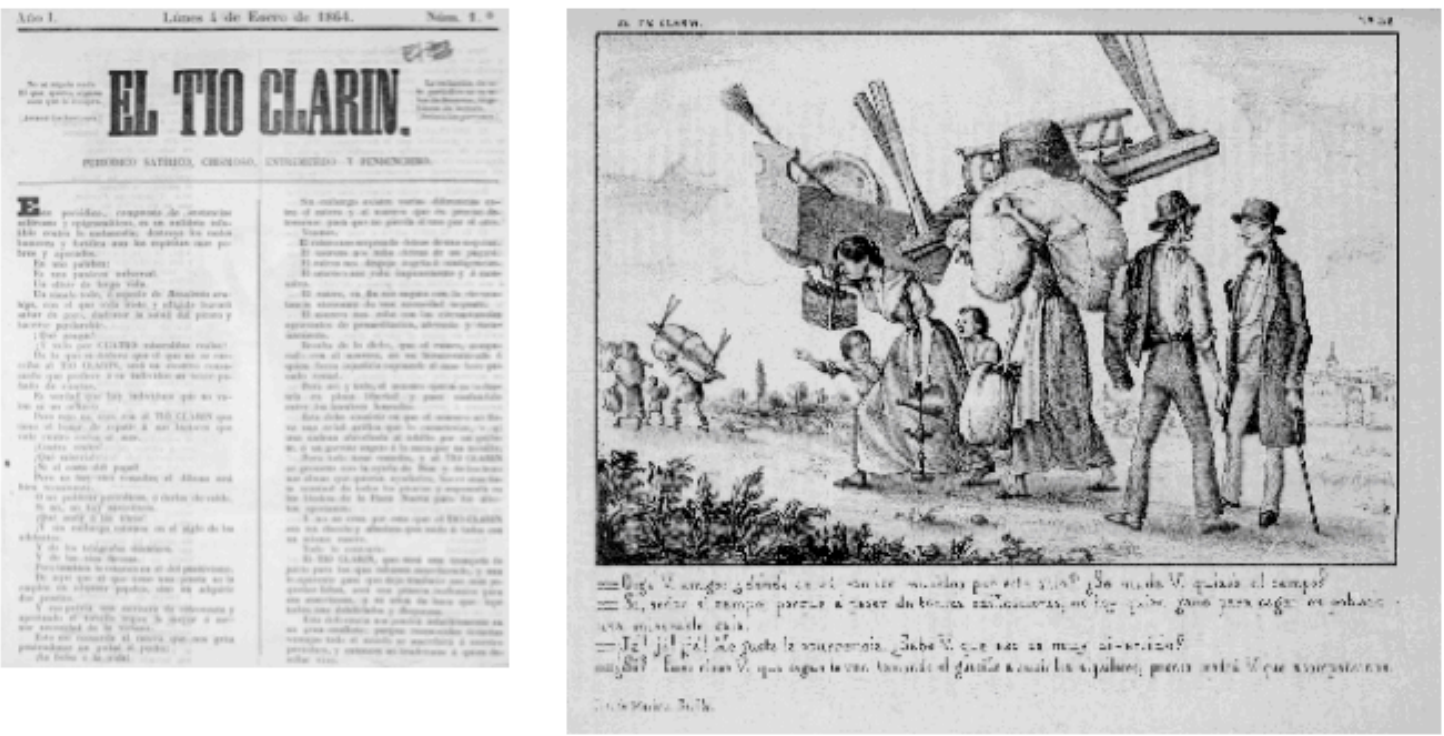

Imagen 2.- Artículo Prospecto de El Tío Clarín N. ํ 1, del 4 de enero de 1864.

Imagen 3.- Lámina litografiada de Luis Mariani. El Tío Clarín, 20 de septiembre de 1864. N. ㅇ 38. Texto:

-Oiga, V. amigo: ¿Dónde se va con los muebles por este sitio? ¿Se muda V. quizá al campo?

-Sí, señor; al campo, por que a pesar de tantas edificaciones, no hay quien gane para pagar en poblado una miserable sala.

-¡Ja! ¡Ja! ¡Ja! Me gusta la ocurrencia. ¿Sabe V. que eso es muy divertido?

-¿Sí? Pues ríase V. que según le van tomando gustillo a subir los alquileres, pronto tendrá V. que acompañarnos.

No suele recurrir a las caricaturas de personajes conocidos, más bien atiende a protagonistas anónimos, con chistera y levita, que dan pie a una crítica sobre ciertas costumbres. También destaca por las aleluyas e historietas, siendo considerado como uno de los pioneros en este género, tratando muy a menudo el plano general con textos dialogados a pie de los dibujos. Referente a los contenidos, Chaves (1995: 163) nos dice:

Muchos de sus artículos tratan sobre asuntos de la localidad, que me parecen de lo más gracioso que aquí se escribió entonces, y merecen ser conocidos, a pesar del poco gracejo y mérito que en Sevilla han tenido las publicaciones de esta índole.

Temas como: El Asilo de Mendicidad de San Fernando al que no dejaban entrar a los pobres, sobre ordenanzas municipales o los buques de gran calado que no podían entrar en el puerto de Sevilla, sobre el sacrificio de perros callejeros para obtener piel para calzado, la carestía de la vida, etc. También recurre a aspectos de la vida del

También colaboró en El Siglo Pintoresco y La Ilustración Republicana Federal (Casado Cimiano, 2006: 109). 
momento, como por ejemplo, la epidemia de cólera ${ }^{20}$ que asoló Sevilla en el año 1865 y que representaba con la imagen de un hindú con turbante y guadaña y en la que llegó a fallecer, por este motivo, el propio alcalde de la ciudad, el señor García de Vinuesa $^{21}$ (su esquela aparece en el n. $\cong 92$ del 30 de octubre de 1865). También, en el n. 107, aparece el artículo "La Trata" que denuncia la esclavitud. Y es que en Sevilla se creó La Sociedad Abolicionista de la Esclavitud, dirigida por el catedrático Antonio Machado y Núñez ${ }^{22}$. Desde esta sociedad organizaron el 26 de enero de 1873 una manifestación antiesclavista en Sevilla para abolir esta práctica en Cuba y Puerto Rico, (Arias, 2009: 388).

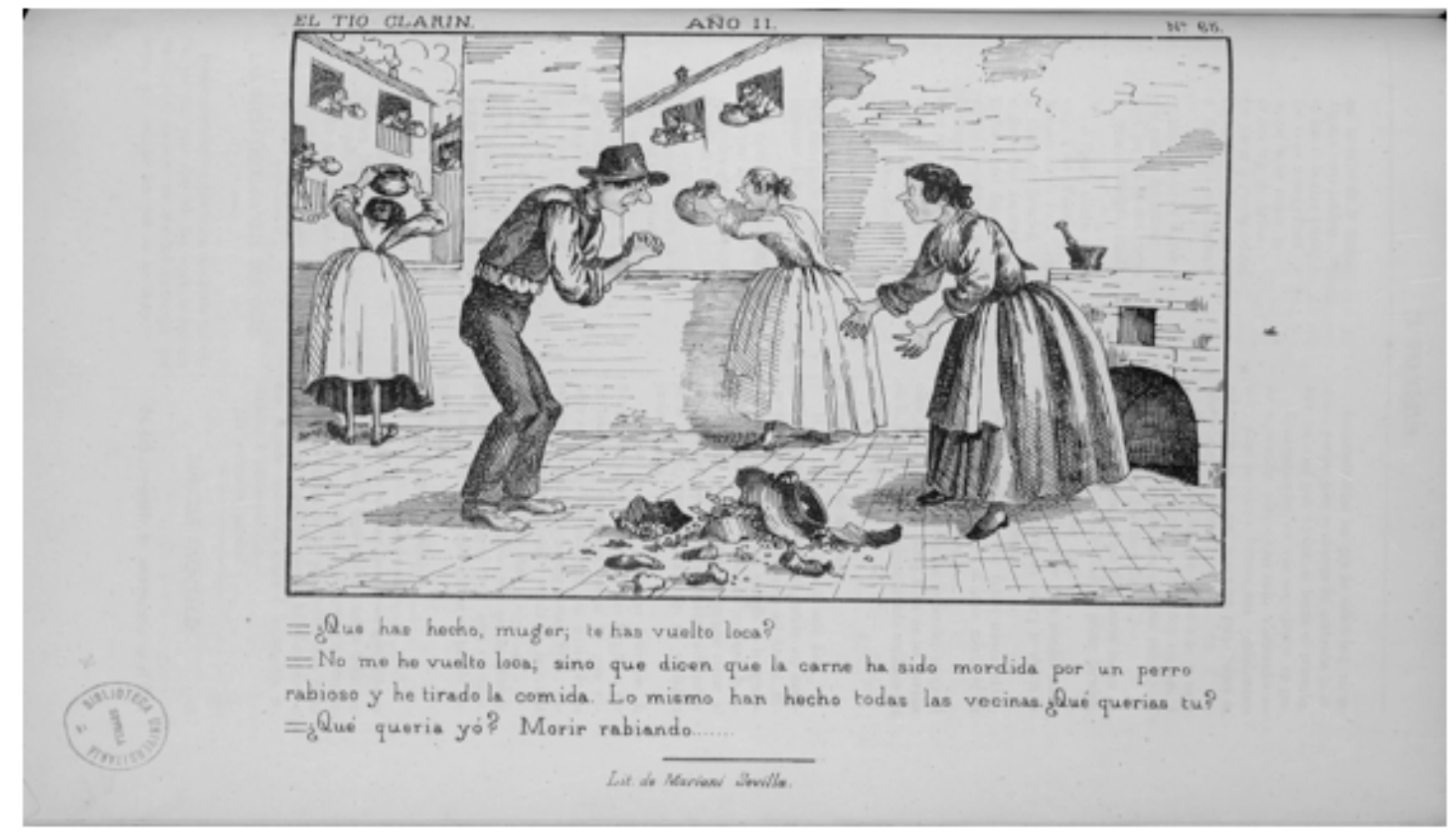

Imagen 4.- Lámina litografiada de Luis Mariani. El Tío Clarín, lunes 27 de marzo de 1865. N. 65 Texto:

-¿Qué has hecho, muger, te has vuelto loca?

-No me he vuelto loca, sino que dicen que la carne ha sido mordida por un perro rabioso y he tirado la comida. Lo mismo han hecho todas las vecinas ¿Qué querías tú?

-¿Qué quería yo? Morir rabiando.

El Tío Clarín dejó de editarse en 1866, y se transformó en el diario político republicano El Clarín (15 de julio de 1867), continuando con la numeración del primero, con una

\footnotetext{
${ }^{20}$ Sevilla tuvo tres epidemias de cólera en este siglo; 1855, 1856 y 1865 (Braojos, 1990: 20).

${ }^{21}$ Alcalde de Sevilla de 1859 a 1865. Destaca por sanear la precaria situación de las cuentas públicas y por el control de pesos y medidas de los mercados, así como de su aprovisionamiento (Cuenca Toribio, 1991: 139).

${ }^{22}$ Antonio Machado y Núñez, catedrático de Mineralogía y Zoología de la Universidad de Sevilla desde 1846. Vinculado al krausismo, como estudioso de las Ciencias naturales y de las doctrinas positivistas y de difusión del darwinismo. También fue Académico de las Buenas Letras. (Arias, 2010: 39-41). Y director del periódico El Hispalense (1870).
} 
edición semanal que contenía caricaturas de Mariani. Después cambiará de cabecera por La Campana (desde el 8 de septiembre de 1867 hasta febrero de 1868), con otra edición semanal con caricaturas del mismo dibujante. Tras numerosos problemas cierra y renace como La Campanilla. Esta sucesión de nombres es denominada por Checa Godoy (2016), como periódicos racimo, y se da cuando una suspensión de cabecera conlleva un nuevo título.

Al parecer, los motivos por los que esta publicación fue cambiando de cabecera en tan breves periodos de tiempo nos lo explica Manuel Chaves (1995: 162-164):

Fue este periódico, político satírico, de los que más popularidad alcanzó en Sevilla. Los trabajos de redacción que en él aparecieron son por lo general intencionados y en extremo chistosos, así como sus caricaturas, que, aunque no muy buenas, tenían intención y chispa: muchas de ellas fueron denunciadas. Habiendo sido suprimido por una denuncia, siguió viendo la luz con el nombre de El Clarín, el cuál también fue objeto de las iras de las autoridades en 1867, fundándose entonces La Campana. Estas tres publicaciones alcanzaron gran fama por los días de la revolución de 1868 a 1870.

Además, en estos años prerrevolucionarios, también se editaron en Sevilla las revistas el El Bú, en 1866, con caricaturas. Y en 1867 Esplandian, con dibujos alusivos al texto, pero cesaron a los pocos meses por falta de suscriptores.

Otra revista interesante fue El Loro ${ }^{23}$ (de 1867 a 1868), (Imagen 5), que sale a la calle en los últimos momentos del reinado de Isabel II, editando 17 números, aunque con un carácter más festivo que satírico. Se subtitula: Revista semanal de colores rabiosos escrita por una sociedad de pajarracos.

El editor era Francisco de Paula Saña y el director Francisco de Sinquemani, también redactor de El Tío Clarín en su primera época. La publicación tenía 4 páginas y en algún número ocho, siendo una de ellas una viñeta lámina. El resto se compone de las secciones Picotazos, Noticias varias y de la Biografía del Loro (protagonista de la revista).

El primer número abre con un Prospecto donde establece cuál sería el estilo del semanario, y dice:

\footnotetext{
${ }^{23}$ Barcelona también editó una publicación denominada El Loro (1879-1885), editada por Víctor Pérez y que nada tenía que ver con la sevillana, (Summa Arts XXXII: 468).

En 1885 nace en Sevilla otra revista denominada El Loro, centrada en temas taurinos y cuyo director fue Isidro G. Quintana (Guía de Sevilla, 1878: 325. Vicente Gómez Zarzuela). Y que tras unas desavenencias entre fundador y redacción pasó a denominarse un año después El Loro Sevillano, también de temas taurinos y se publicaba los días de corridas (ibíd, 1995: 275).
} 
Ante la falta de periódicos que valga la pena leerse en Sevilla, aparece El Loro que será una enciclopedia de artículos agridulces, verdades amargas, camelos, oportunidades, agudezas, cuentos, epigramas, semblanzas, charadas... que van preñadas de malicia y repletas de proyectiles. Saldrá todos los lunes y la emprenderá a picotazos.

En sus textos pueden leerse numerosos comentarios críticos sobre la Sevilla de entonces: sobre los teatros San Fernando y el Duque para que sus espectadores dejen de fumar; sobre el mal estado de las losetas de la calle Velázquez o un boquete en la calle Alcaicería; los niños alborotadores que hay por la calle Tetuán; las farolas, que las apagan a media noche, entre otras... Hechos que también recogía la prensa diaria sevillana, como cita el profesor Manuel Cuenca Toribio (1991: 158-161):

Los incisivos redactores de La Crónica, El Porvenir, El Farol, El Centinela, La Andalucía, El Sol... revelaron su gran dominio de la vis satírica al ironizar sobre los baches en que se hundían los carruajes y peatones y las lobregueces de los barrios con sus farolas a gas (1578 en 1863) y aceite (920 en el mismo año) con frecuencia apagadas o a media luz (...) Y es que hasta 1874 no comenzaría en Sevilla la instalación del alumbrado eléctrico.

El dibujante de El Loro fue el pintor Teodoro Aramburu y Murua (Imagen 6). Premiado en la exposición Nacional de Bellas Artes de 1881 con el cuadro "Apaga y vámonos: Dos hermanos del rosario de la Aurora de Sevilla", (Cascales Muñoz, 1929:35). Fue dibujante de La Giralda (1868), El Alabardero (1877) y el periódico literario ilustrado EI Renacimiento (1884). Ilustró retratos para una serie de libros de "Anales del Toreo" que dirigió Francisco Arjona. También tenía un taller de fotografía en calle Sierpes 112 en el año 1878 (Guía de Sevilla, 1878: 305-393). 

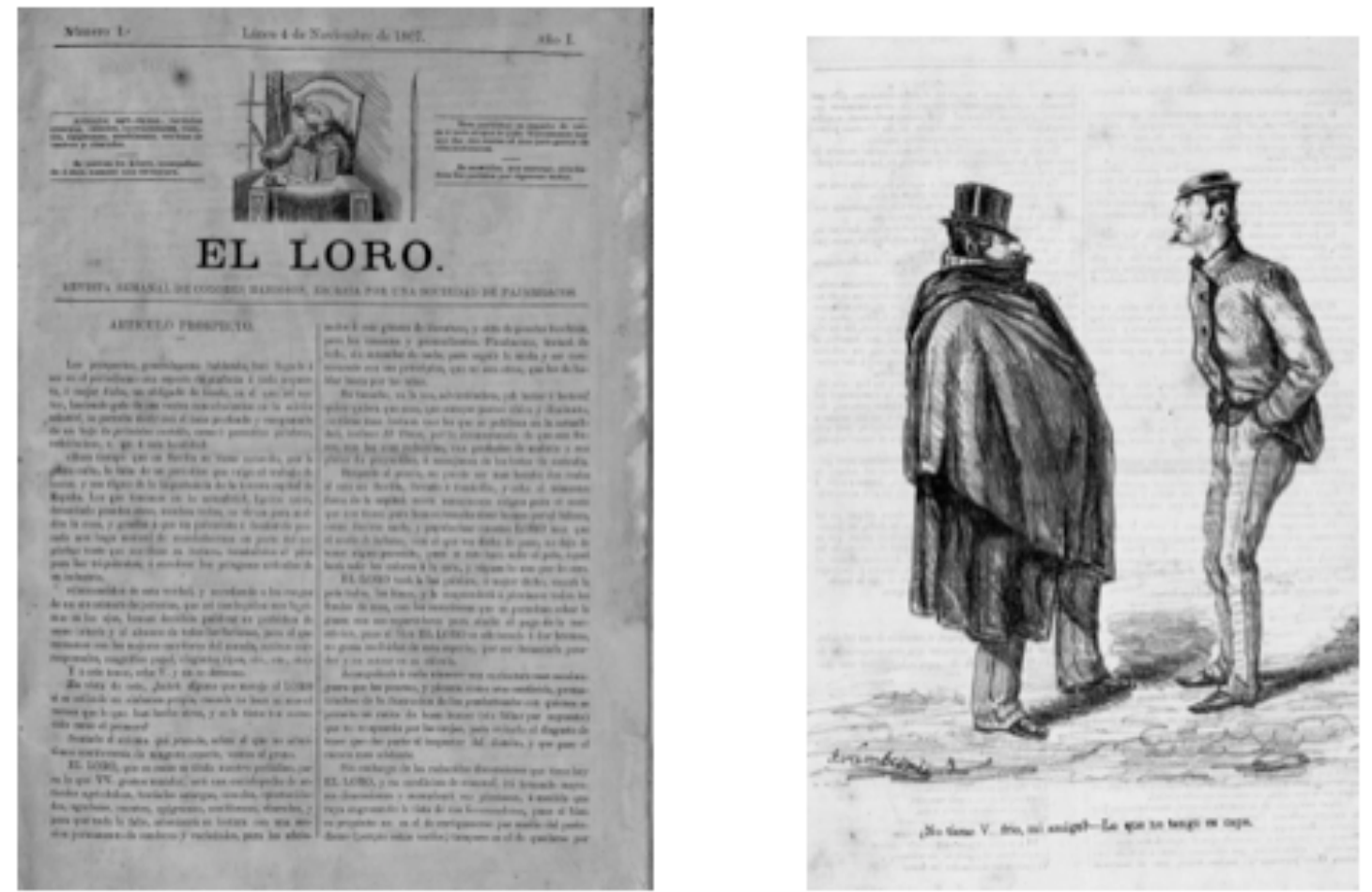

Imagen 5.- Portada de El Loro, número 1, del 4 de noviembre de 1867

Imagen 6.- Viñeta de Teodoro Aramburu en el n.o 5 de El Loro. Diciembre de 1867.

Texto: ¿No tiene V. frío, mi amigo? -Lo que no tengo es capa.

Aunque algunas de las viñetas no llevan firma es fácil reconocer su trazo y estilo. En ellas ilustra personas de la época; de paseo, matrimonios, carnaval, mendigos... con chistes que hoy día consideramos muy viejos y que también lo eran ya a finales del siglo XIX, como nos cuenta Manuel Chaves (1995: 175): "Los números que tengo a la vista de El Loro están escritos con cierto chiste algo pasado hoy. Los dibujos son de escaso mérito e ingenio, aunque revelan intención".

Otro ejemplo es el dibujo del n. $\stackrel{12}{12}$ donde la viñeta refleja a dos soldados, y uno dice: "Lleva mucho tiempo de cabo". Y el otro responde: "Me llaman el cabo Finisterre".

Aún siendo unas ilustraciones de buena calidad estética observamos que sus temáticas y contenidos son muy inocentes, sin carga crítica, intentando buscar una gracia caricaturesca en la pose o vestimenta de los protagonistas. No obstante, Aramburu, mostrará una mayor evolución plástica desde la revista El Alabardero.

La revista El Loro se mantuvo en la calle solo durante cuatro meses, posiblemente por los obstáculos e inconvenientes que aplicaba el gobierno, ahora conservador, a las leyes de imprenta.

Los últimos gobiernos moderados del andaluz Narváez y sobre todo el gobierno de Luis González Bravo, 1867-1868, marcan el definitivo retroceso de la libertad 
de expresión, que justifica la explosión contraria con el triunfo de la Gloriosa, (Checa, 2011: 122).

\section{La Gloriosa desde las revistas satíricas sevillanas}

La situación política en España fue muy inestable durante los últimos días del reinado de Isabel II:

El descontento social por el desempleo y la subida de precios" (Braojos, 1990: 21), junto con: "El autoritarismo, la intransigencia exclusivista y la inmoralidad pública con que se había ejercido el poder en los últimos años de la monarquía de Isabel II llevaron a la formación de una coalición integrada por unionistas, progresistas y demócratas que acabó derrocando dicho régimen. Se llevó a cabo con un pronunciamiento militar seguido de una movilización popular en medio de un entusiasmo regenerador. (Arias, 2009: 13).

Estos motivos provocarán el estallido de la Gloriosa, y abarcará de 1868 hasta 1874, etapa conocida como el Sexenio Revolucionario, y en la que también tendrán lugar la monarquía de Amadeo de Saboya, la I República española y los gobiernos Cantonales.

Estos sucesos transcendentales quedaron recogidos en la prensa sevillana de todos los signos políticos ${ }^{24}$, incluidas las revistas satíricas, que se radicalizarán, pasando del estilo artístico costumbrista al estilo naturalista de crítica social, moral y política, desarrollando una imagen jocoseria y esperpéntica en la prensa ilustrada (Summa Artis, XXXII), debido a una mayor libertad de expresión con la ausencia de censura y fianzas. En las viñetas se critica todo y de una manera grotesca y exacerbada.

Y donde mejor podemos seguir el desarrollo de la revolución de septiembre de 1868 en Sevilla es a través de la revista La Giralda ${ }^{25}$, (Imagen 7), de carácter festiva en un principio y revolucionaria después. Nació en Sevilla el 7 de mayo de 1868 y durará unos seis meses, viviendo los momentos de la Gloriosa.

La revista estaba enumerada en 'repiques' de campana. Entre sus firmas (seudónimos) encontramos a cargos y personajes afines; el Campanero, Quasimodo, el Murciélago, el Acólito, el Giraldillo...

\footnotetext{
${ }^{24}$ Un registro de las cabeceras de estas fechas aparece en el libro de Arias Castañón, (2009): Ideología y Política en Sevilla bajo la Monarquía de Amadeo de Saboya y en el de Checa Godoy, (2016): Censo de la prensa española del sexenio democrático 1868-1874".

${ }^{25}$ En el año 1882 aparece otra revista festiva denominada La Giralda. Y de nuevo otra en 1893, ésta dirigida por J. M. García Rufino, director de Don Cecilio de Triana a principios del s. XX.
} 
Como anécdota de publicación festiva citamos uno de los repiques del primer número (7 de mayo de 1868):

En la preciosa torrecilla de la Casa Consistorial se está colocando el magnífico reloj obra del señor Losada que tantos elogios ha merecido por parte de la prensa. Se dice que dará horas, medias horas y hasta cuartos. Esto último nos ha parecido inverosímil. ¿Quién se atreve a dar cuartos en los tiempos que corren?

Meses después, en el repique n.ㅇ 20, del 21 de septiembre de 1868, con la Gloriosa en marcha, toma parte de la contienda:

Próximo de entrar en prensa nuestro periódico, el grito de iViva la libertad! unánimemente lanzado por el pueblo de Sevilla ${ }^{26}$ y las tropas de la Guarnición, mandadas por el general Izquierdo, resonó en todos los ámbitos de la capital. En la imposibilidad de dar más noticias sobre tan fausto suceso, nos limitamos a exponer la franca manifestación de nuestros sentimientos que unidas al programa de la Junta Revolucionaria encontrarán nuestros lectores en la cuarta plana de este número. Firmado Ramón Abascal.

En la cuarta plana aparece un manifiesto titulado iViva la Libertad! ${ }^{27}$ Donde establece un decálogo de principios revolucionarios: Sufragio universal, libertad de imprenta, libertad de enseñanza, de cultos, industria y de comercio, la abolición de la pena de muerte, de las quintas, declarando el derecho de seguridad individual e inviolabilidad del domicilio y correspondencia, así como elecciones para unas Cortes constituyentes $^{28}$.

Recordemos que tres días antes, el 18 de septiembre de 1868 estalló en Cádiz la sublevación militar, conocida como la Gloriosa dirigida por el brigadier Topete y a la que se unieron los generales Serrano y Prim, que derrotan a las tropas del gobierno el 28 de septiembre, en Alcolea del Río (Córdoba), por lo que la reina se exilió a Francia.

\footnotetext{
${ }^{26}$ Sevilla se unió a la revolución con el mariscal de campo Rafael Izquierdo, quien constituyó en el Ayuntamiento la Junta Provincial Revolucionaria el día 19 de septiembre, lo que supuso "el despido de la aristocracia y de los alto-burgueses sevillanos de los ámbitos del poder y el ascenso a éstos de quienes, si no unidos en lo ideológico, ostentaban el denominador de ser otras capas de la burguesía", (Braojos, Parias y Álvarez, 1990.Tomo I: 23).

27 Este manifiesto estaba firmado por Antonio Aristegui, Rafael Izquierdo, Felipe Rubio, Joaquín Peralta, Juan José Hidalgo, Fco. Javier Caro, Fco. Díaz Quintero, Felipe Álvarez Sotomayor, Manuel Carrasco, Antonio Machado, Manuel Pastor, Manuel de la Puente y Pellón, Tomás Arderius, marqués de la Motilla, Federico Castro, Manuel Laserna y Manuel Sánchez Silva.

28 Muchas de estas reivindicaciones serán los temas de las viñetas y caricaturas que aparecerán durante el Sexenio Revolucionario en muchas publicaciones, como por ejemplo en Gil Blas, La Flaca o El Padre Adam, entre otras.
} 

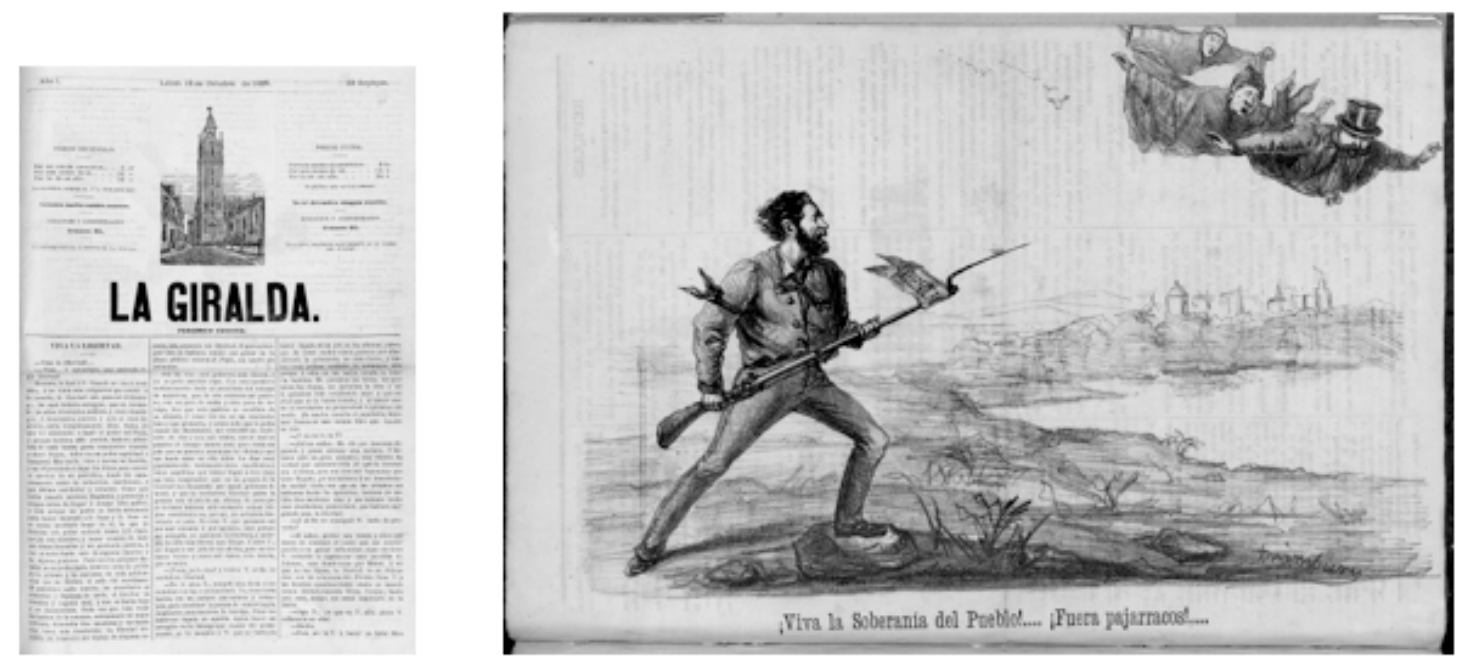

Imagen 7.- Portada de la revista La Giralda. 12 de octubre de 1868. Repique 23.

Imagen 8.- Ilustración de Teodoro Aramburu en La Giralda en el número o repique 23

Texto: ¡Viva la soberanía del pueblo!... ¡Fuera pajarracos!... (Un noble, un hindú y una monja).

En el repique 21 del 28 de septiembre de 1868, y en pleno proceso revolucionario, ya aparecen ilustraciones realizadas por diferentes dibujantes locales. La primera viñeta simboliza la crudeza con la que se vivían esos días. En ella se reedita un dibujo donde se observa a varias personas ahorcando ${ }^{29}$ a un señor, con el pie de texto:

El bello ideal de la justicia humana es ahorcar a un ministro. Palabras de D. Luis González Bravo. Impresas en el periódico El Guirigay (1837-1839), fundado por Luis González Bravo ${ }^{30}$, el miércoles 13 de marzo de 1839.

En el repique 22, del 5 de octubre, caricaturas de González Bravo y la reina dejando el erario público vacío. En el repique 23 dibuja Aramburu, (Imagen 8). En el repique 24, aparece una aleluya de 8 viñetas narrando las aventuras de Sor Patrocinio, sin firma. Igual que en el repique 25 , donde la viñeta representa la huída de la reina y otras personas en burro, cargado con una caja (de caudales) dirección a Francia.

A La Giralda le hará compañía en diciembre de 1868 El Padre Adam, (Imagen 9). Subtitulada Publicación satírica, de política y costumbres, con caricaturas y láminas de actualidad y otras cosas que verán los hijos de Adam e hijas de nuestra madre Eva. El

29 "El ahorcamiento, el pender de una cuerda del cuello, fue practica de la caricatura francesa y de la británica, en especial de Gillray, pero también Goya incluyó el tema, y lo desarrolló, en sus Desastres de la guerra" (...) "En las revoluciones como en las contrarrevoluciones el enemigo es demonizado, de tal modo que solo cabe su destrucción". Introducción de V. Bozal en Lo cómico y la caricatura y El pintor de la vida moderna de Charles Baudelaire (2015, p. 25).

30 Don Luis González Bravo fue el último presidente del gobierno bajo el reinado de Isabel II y también se exilió junto a la reina. Se da el caso de vinculación entre prensa y política, como Cándido Nocedal, que fue director de la revista satírica madrileña El Padre Cobos (1854-1856) y después, ministro de Gobernación en el gobierno conservador de Narváez. 
director y dibujante fue Luis Mariani, que dejaría El Clarín en $1868^{31}$. La revista fue: "republicana, beligerante en su federalismo, ocurrente y ácida", (Checa, 2011: 191). Publicó más de 122 números o 'visitas' con paginación correlativa desde diciembre de 1868 hasta noviembre de 1870 y cerró por la persecución que sufrieron los vendedores y la imprenta donde se editaba por la prohibición de vocear los contenidos de los diarios y revistas (Arias, 2001: 184).
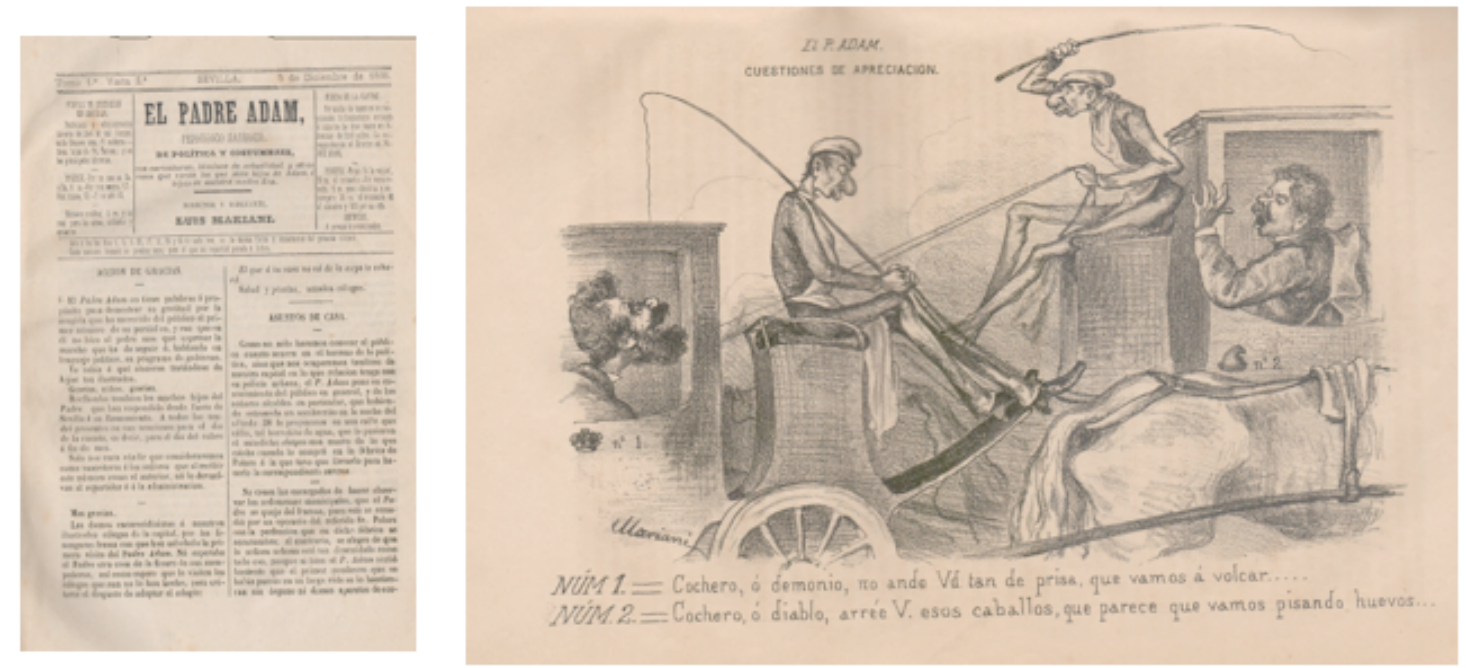

Imagen 9: Portada del primer ejemplar de El Padre Adam.

Imagen 10: Viñeta de página entera de Mariani en El Padre Adam, n. ㅇ 17 del 3 de febrero de 1869.

Texto: Núm.1= (carroza con emblema monárquico). Cochero, o demonio, no ande $\mathrm{Vd}$. tan de prisa que vamos a volcar...

Núm.2 = (carroza con emblema republicano). Cochero, o diablo, arrée V. esos caballos, que parece que vamos pisando huevos...

El personaje padre Adam (en enero de 1870 cambia a El Padre Adán), es un tipo que aparece desnudo, tan sólo vestido con una hoja de parra, gafas, chistera y alzacuellos con lazo de corbata. En la mano lleva varias varas de espino, ya que reparte sus sátiras desde la sección 'Flores del paraíso (con espinas)'.

Habla de noticias en general, realizando una campaña contra el impuesto de Capitación del ministro de Hacienda Figuerola y después de Ardanaz (impuesto que grava por igual a todas las personas, independientemente de su renta).

En esta etapa Mariani realiza viñetas y alguna historieta, mostrando un cierto parecido a las ilustraciones de Ortego en Gil Blas, al dibujar personas muy estiradas y delgadas (imagen 10). También, a la hora de caricaturizar políticos, repite las características y deformaciones que ya realizaban otros dibujantes (suponemos que los de Gil Blas y La Flaca), siendo fácilmente reconocibles ciertos protagonistas del momento desde cualquier publicación; la cabeza puntiaguda de Sagasta, los rizos de Salustiano Olózaga,

\footnotetext{
${ }^{31}$ En la visita n.o 7 del 25 de diciembre de 1868 nos dice que: "El director de esta revista, el señor Mariani, se ha separado de la redacción de El Clarín para atender El Padre Adam.
} 
el perfil de la reina Isabel II, además de un sinfín de bigotes y perillas, como los de su marido Francisco de Asís de Borbón, el duque de Montpensier, Topete, Castelar, etc. También se comentan noticias internacionales como la Guerra Franco-prusiana entre Napoleón III y Bismark, este último caracterizado con el casco prusiano.

Al tiempo que El Padre Adam se reparte en las calles de Sevilla, nace también en la capital hispalense la revista La Zurra, con un estilo político moderado, y en la que destacará otro gran dibujante, como fue José Chaves.

En febrero de 1869 se publicaba el primer número de un nuevo semanario satírico titulado La Zurra, de cuya aparición dieron cuenta en palabras afectuosas la mayor parte de los diarios de entonces y El Porvenir decía en su número del 2 de marzo: Hemos recibido los primeros números de esta chispeante y graciosa publicación satírica, a la que hacen notable no solo su redacción, sino sus oportunas caricaturas, perfectamente dibujadas. (Chaves, 1904: 15).

La Zurra se define como un periódico libre, (aunque apreciamos en sus textos un compromiso hacia Emilio Castelar ${ }^{32}$. De subtítulo lleva: 'Se reparten cuatro palizas a domicilio por 4 reales al mes'. Aunque en el n. -2 (28 de febrero de 1869) advierten a los lectores: "En vista de la buena acogida van a dar cinco palizas en vez de cuatro".
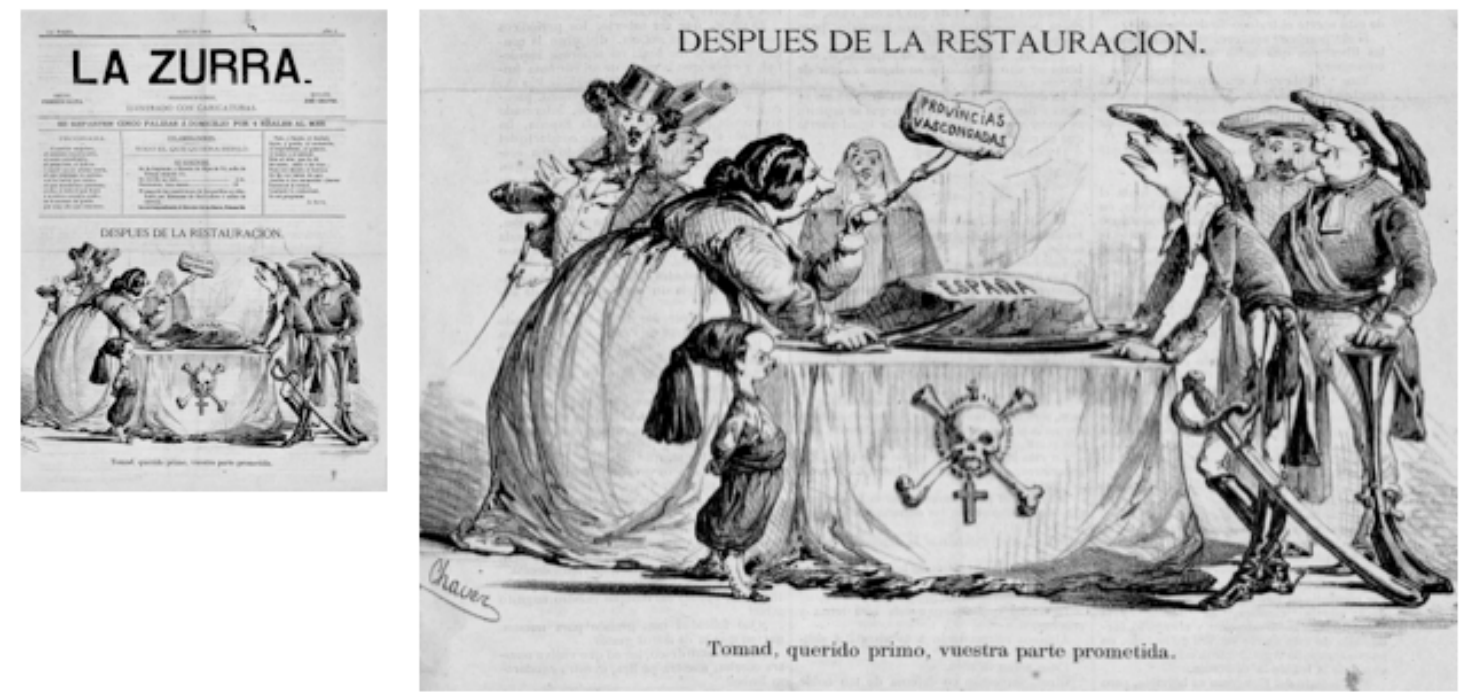

Imagen 11.-. Portada de la revista La Zurra con una viñeta de José Chaves. Mayo de 1869 y detalle de la viñeta: La reina Isabel II junto a su hijo Alfonso XII, entrega las Provincias Vascongadas (un trozo de carne del asado España), a su tío Carlos VII con la típica boina carlista. Los seguidores de Isabel II, Ilamados neocatólicos, se entregarán a las fuerzas carlistas por ser católicas y tradicionalistas. En un segundo plano Sor Patrocinio, el padre Claret, confesor de la reina y Francisco de Asís, rey consorte

\footnotetext{
32 Emilio Castelar y Ripoll (Cádiz, 1832-Murcia, 1899). Político, periodista y escritor. Jefe de Estado de 1873-4. Partidario de un republicanismo unitario y conservador.
} 
En sus textos y viñetas encontramos críticas a Sagasta, a los ministros de Fomento, de Ultramar... A la Iglesia, a la candidatura monárquica de los Montpensier frente a la república, al saber frente a la intolerancia... En su interior también hay sonetos, epigramas, charadas, última hora y los "zurriagazos" donde critican al Ayuntamiento por talar más de un kilómetro de arbolado por los caños de Carmona y a la administración de Correos por el retraso en recibir la prensa madrileña republicana frente a la monárquica, entre otros temas. En el número 3 cierra el periódico con la noticia Última Hora: Las doce.

El director de la revista fue Federico Salva y el dibujante José Chaves Ortiz (Sevilla 1839-1903), con excelentes viñetas políticas (Imagen 11 y 12). Chaves nos dice (1904: 15):

Y a juzgar por las que he visto y poseo (viñetas), se explica la aceptación que obtuvo aquel semanario donde escribieron Luis Escudero y Perosso, Federico Utrera, Mariano Caos, Eduardo Montesinos y Felipe Pérez González (...) Solo vivió ésta unos 20 números, pero su circulación fue extraordinaria, llegando entre ciertos elementos a causar gran marejada aquellos dibujos tan intencionados y valientes pudiendo el autor apreciar, por los aplausos de unos y los apasionados juicios de otros que su obra no era de esas que caen al vacío y son acogidas con total indiferencia.

El origen artístico de José Chaves procedía del taller del pintor Antonio Cabral Bejarano y de la Escuela de Bellas Artes, formando parte del grupo de fundadores de la Academia Libre de Bellas Artes de la ciudad en 1872 y de la que fue profesor. Diseñó la cabecera del diario El Cristiano (1869), de confesión protestante e llustró también las obras de José Velázquez y Sánchez, "Anales de Sevilla de 1800 a 1850", con doce retratos de personalidades de Sevilla y en los "Anales del Toreo", con seis láminas, siendo la temática taurina en la que desarrolló la mayor parte de su obra. También ilustró el primer cartel de la Fiesta de primavera de Sevilla en 1878 (Villalba Díaz, 1991).

Colaboró en los periódicos taurinos de Madrid La Lidia (1883-1889), con 67 láminas cromolitografiadas de gran calidad, que recogían diversas suertes de la corrida, (EI Liberal, 25 de septiembre de 1903), (Chaves, 1904: 44), y La Nueva Lidia con 8 láminas, y en el sevillano La Fiesta Española en 1887, (Casado Cimiano, 2006: 64).

Valdivieso dice sobre José Chaves (1980: 112):

Como complemento a su actividad pictórica debe mencionarse también su colaboración como caricaturista en periódicos locales de carácter satírico como La Zurra. Estas caricaturas muy celebradas por su mordacidad, causaron el regocijo entre el público sevillano y por el contrario mortificaron a los protagonistas de las mismas. 
Por último, su hijo Manuel Chaves Rey, (1904: 16), comenta que su padre: “José Chaves Ortíz no volvió a publicar más dibujos de aquel género. El artista sevillano se dedicó, como hasta allí había hecho, al arte serio, al estudio del natural y a la pintura de género". Aunque, y continúa escribiendo: "Su amigo el librero, editor e impresor de la revista, Fernando Fé le animaba a trasladarse a Madrid donde la prensa satírica podría brindarle mucho campo y en donde más de uno que poseyó menos condiciones que él logró fama y provecho".

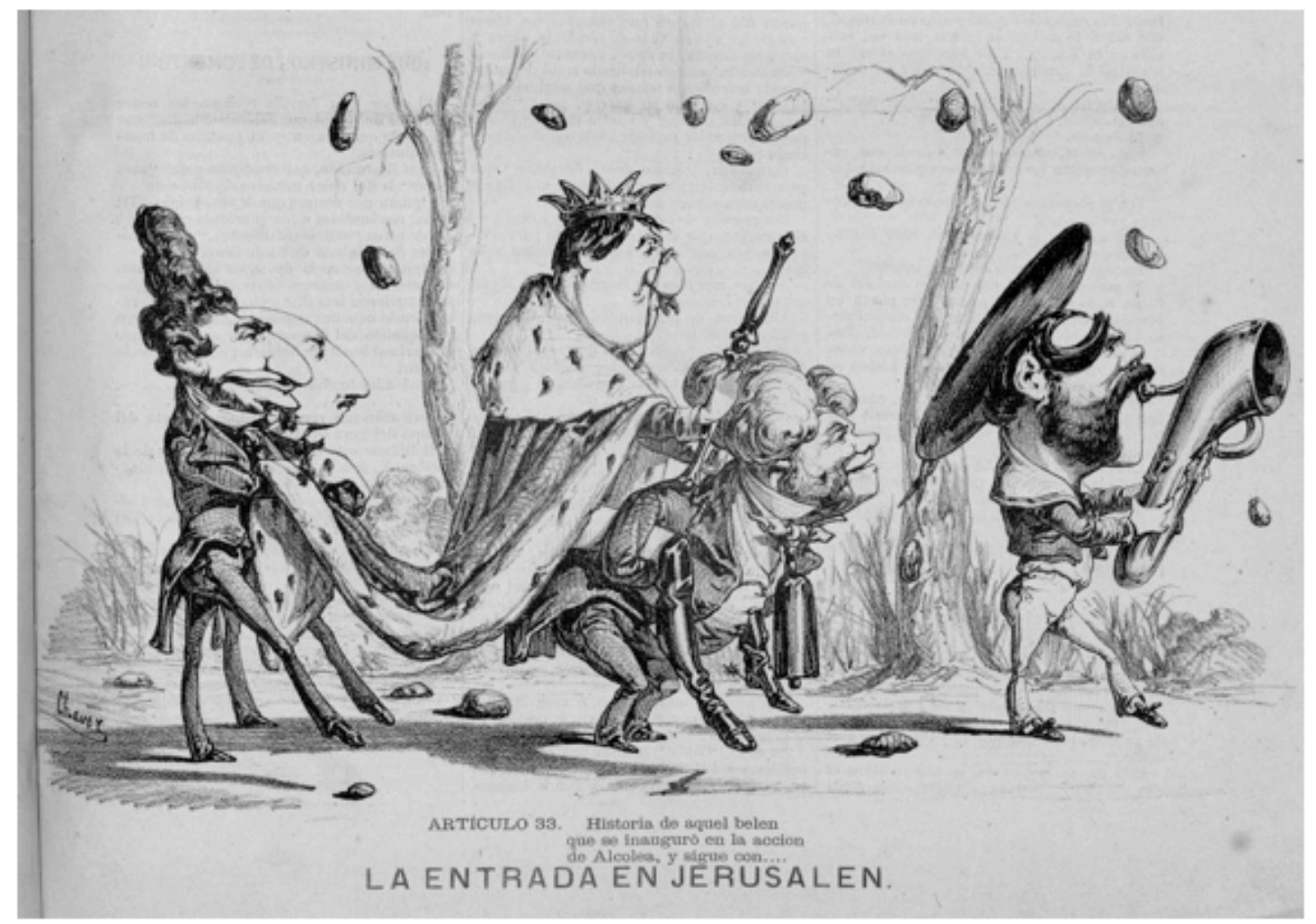

Imagen 12. Viñeta de la portada de La Zurra realizada por José Chaves. Junio de 1869. Título: La Entrada en Jerusalén. La prensa republicana cuestionaba a los candidatos a la corona española como, en este caso, al duque de Montpensier, que es llevado a 'lomos' de Salustiano Olózaga (embajador español en París). Detrás los líderes Práxedes Mateo Sagasta junto a Serrano y delante, el almirante Topete vestido de marinerito.

Otras revistas con ilustraciones que aparecieron en estos años en Sevilla fueron El Diluvio (1870) suplemento satírico del diario La Fraternidad, (Checa, 2011: 193). Y en 1872 y dirigida por el utrerano Diego Sedas, la revista La Charanga ${ }^{33}$.

\footnotetext{
${ }^{33}$ Según Manuel Barrero (2011: 22), ya existió en 1857 otra revista satírica con el mismo nombre, pero editada en Cuba (en estos años era española), por Juan Martínez Villergas y considerada la primera revista española que contenía historietas. El dibujante era Víctor Patricio de Landaluze.
} 


\section{Dibujantes sevillanos en la prensa satírica nacional durante la Gloriosa y la Restauración}

Será en los años del destronamiento de Isabel II cuando surgieron en las principales ciudades de España las mejores publicaciones joco-serias y humorísticas del siglo XIX, algunas de muy larga duración y con ilustraciones de gran calidad artística y satírica.

Así, por ejemplo, nacieron en 1869 en Barcelona El Guirigay, La Flaca (semanario político, republicano y federal) y La Gorda (su réplica conservadora). Un año después La Campana de Gracia (Barcelona, 1870-1936). También L'Esquella de la Torratxa (1872-1939) y Barcelona Cómica. De Madrid destaca El Mundo Cómico en 1871.

Además de éstas, se popularizan otras publicaciones denominadas como prensa seria ilustrada, donde muchos dibujantes van a colaborar, convirtiéndose los ilustradores y caricaturistas en auténticos profesionales.

Hay que entender cómo el dibujante-caricaturista cumple en la prensa del siglo XIX las funciones de auténtico periodista gráfico, unas veces como crítico irónico de su sociedad y otras, de manera más amable, como simple cronista de salón, encargado de mostrar a los lectores la imagen de los acontecimientos de actualidad (Martín, 1979: 13).

Un ejemplo fue Tomás Padró (1840-1877), dibujante que simultaneará ambas funciones cuando a partir de la Revolución del 68 refleje con su lápiz el espectáculo de la vida política española con caricaturas en La Flaca (1869-1876), y como cronista de sociedad en La Ilustración Española y Americana (1869-1921). Esta revista, con sus 16 grandes páginas de textos y grabados llegó a ser la gran revista ilustrada de la burguesía del último tercio del siglo XIX. (Martín, 1979: 13).

En esta situación estuvo también Valeriano Bécquer (Sevilla, 1834-Madrid, 1870), que dibujó en La Ilustración de Madrid (1870-1871), desde principios de 1870 hasta septiembre, cuando fallece (Valdivieso, 1981: 58). Sus ilustraciones aparecieron también en El Bazar (1874)" (Bozal, 1989: 72-74), y en la primera época de Gil Blas, además de en los almanaques de este periódico y en la revista La Píldora (Casado Cimiano, 2006: 68). Sin olvidarnos de su posible autoría en las estampas de "Los Borbones en Pelota".

Después de la Gloriosa y de la huída de Isabel II, en noviembre de 1869 se realizaron elecciones a Cortes y se elaboró una constitución en la que se decidió mantener el régimen monárquico 'democrático', aunque laico y con libertad de cultos, instaurando el sufragio universal y recogiendo los Derechos del Hombre. 
Se constituyó un gobierno provisional, nombrando regente del país a Serrano (unionista) y presidente del gobierno a Prim (progresista). Mientras, se presentan candidatos a la corona y en este casting de pretendientes estaban; el príncipe Alfonso (futuro Alfonso XII e hijo de Isabel II); Carlos VII (Carlista y tío de la reina); el duque de Montpensier (cuñado de la reina Isabel II); el ex rey de Portugal; el príncipe alemán Leopoldo de Hohenzollern, candidato propuesto por Bismark; el general Espartero que rehusó ser candidato, y Amadeo de Saboya, hijo del rey de Italia Víctor Manuel II, anticlerical e izquierdista, que saldría elegido como rey de España desde el 2 de enero de 1871 hasta el 11 de febrero de 1873 en que abdica. Entonces, las Cortes proclamaron la República como forma de gobierno de España hasta enero de 1874, cuando el general Pavía da un golpe de estado, provocado por el caos de convivencia política entre partidos; por las autoproclamadas repúblicas independientes o fenómeno de los Cantones sin contar con el poder central, (Sevilla se hizo independiente de Madrid, y a la vez Utrera se independizaba de Sevilla); las barricadas; las deserciones de la tropa; los problemas de sublevación en Cuba y la insubordinación y anarquía, que hasta hizo huir a Figueras, primer presidente de la República (Comellas, 1977: 48-52).

El golpe de estado del general Pavía puso fin al Sexenio Revolucionario y proclamó rey de España a Alfonso XII, que reinará de 1874 hasta 1885, año en que fallece. El trono lo heredará entonces su esposa María Cristina, de 1885 hasta 1902, y cumplida la mayoría de edad, su hijo póstumo, el rey Alfonso XIII, de 1886 a 1931.

Durante estos años los partidos políticos conservador y liberal se fueron turnando en el gobierno, en una etapa histórica conocida como la Restauración y que finalizará con la dictadura del general Primo de Rivera en el año 1923.

Esta época del turnismo de Cánovas del Castillo y Sagasta, va a procurar una verdadera apertura y evolución en cuanto a la libertad de prensa. Según M. a José Ruiz Acosta:

Situándola como el lugar idóneo para establecer debates y cuestiones constitucionales, aunque prohibiendo atacar a la Corona (Decreto de 29 de enero de 1875). Eliminando la censura previa (Constitución de 1876), conjugando libertad de prensa con una autocensura frente a la monarquía (Ley de Imprenta de 1879), anulando la pena de suspensión a los periódicos y sanciones a periodistas (Real Decreto de 14 de febrero de 1881), y por último la Ley de Policía de Imprenta de 26 de julio de 1883, que eliminaba las legislaciones específicas en materia de imprenta que no estuvieran contempladas en el Código Penal. Este hecho, y un contexto económico favorable, dieron paso al nacimiento del periodismo moderno, la industrialización de sus empresas y su progresiva transformación en empresas organizadas. (Reig y Ruiz Acosta, 1998). 
Una de las publicaciones satíricas andaluzas de esta nueva época será El País de la Olla (Málaga, 1881-1883), dirigida por Emilio de la Cerda (1841-1923). La cabecera de El País de la Olla hacía referencia a la olla del Estado -el presupuesto- y criticaba como los gobiernos de turno repartían entre los suyos las jefaturas de ministerios, capitanías, y la administración en general, (Arcas Cubero, 1990: 60).

A nivel nacional sobresalen las revistas La Filoxera, Madrid (1881), El Motín, Madrid (1881), La Mosca, Barcelona (1881), La Broma, Madrid (1881), La Caricatura, Madrid, (1884), y Gedeón, Madrid (1895).

Es en esta época cuando también despuntan algunos dibujantes sevillanos en Madrid, como Pedro de Rojas (1872-1947):

Ilustrador de aleluyas e historietas, dibujante junto con Ramón Cilla en la revista La Gran Vía (1893), donde destaca por su madurez y ésta se refleja en una serie de historietas cortas, muchas de ellas de dos o tres viñetas, con textos muy breves o absolutamente mudas. Se trata de trabajos ocasionales, que cumplen funciones de relleno en la revista y son utilizados para cubrir los espacios muertos dejados por las colaboraciones literarias, pese a lo cual son superiores a los de Cilla, tanto en dibujo como en perspectiva y composición, dándonos la imagen de un autor que ha estudiado a los dibujantes extranjeros y ha sabido aprender las peculiaridades del lenguaje del cómic. También colaboró en El Tío verdades, Blanco y Negro (desde 1891) y El Gato Negro (Martín, 1979: 30). Y en El Cardo (1894), y Madrid Cómico (1880-1902). (Summa Artis XXXII: 470).

Otros ilustradores sevillanos en revistas madrileñas de carácter serio como La Ilustración Española y Americana (1869-1921) fueron los pintores Luis Jiménez Aranda (1845-1928), y su hermano José Jiménez Aranda, que también dibujó en El Mundo Ilustrado. Y Domingo Fernández González (1862- ), también pintor y catedrático de dibujo del Instituto Europeo de Buenos Aires, donde residió desde 1910. Éste colaboró en La Ilustración Artística, La Ilustración Católica, Álbum Salón y Blanco Negro (1891), (Casado y Cimiano, 2006: 75). En esta última revista también dibujó el sevillano Manuel García Rodríguez (1863-1925), pintor paisajista (Valdivieso, 1981: 128).

\section{La Restauración Borbónica y las revistas festivas sevillanas}

Este boom de prensa seria ilustrada, también se dio en Sevilla con la aparición de El Gran Mundo (1873), El Eco de Sevilla (1880), La Ilustración Bética (1881), La Prensa (1882), La llustración Andaluza, El Renacimiento (1884), la taurina El Burladero (1885), La Literaria Festiva de 1890, Sevilla Artística y La Biografía Ilustrada (1892) y Andalucía 
Ilustrada. Prácticamente todas ellas incluían algún tipo de ilustraciones, cromos, litografías y retratos en fotograbados.

Del periodo de la Restauración en Sevilla son las revistas El Recreo (1874) y El Alabardero (1877), (Imagen 13), esta última con dibujos de T. Aramburu, T. Povedano y Blas (Imagen 14), este último desde 1880 a 1885. El Alabardero Se publica los días aciagos, decía el subtítulo. Después cambió a Periódico de Intereses Materiales, Teatros, Toros, Caza, Regatas, Equitación, Gimnasia, Esgrima, todo por un perro grande (moneda de la época). Entre sus directores estaban Manuel Padilla Salvador, Juan Pérez Gironés y Mariano Casas. Era un periódico festivo de críticas a las representaciones teatrales de las salas El Duque, Cervantes y San Fernando y desde la sección Alabardazos soltaba sus indirectas y críticas. Las viñetas, algunas sin firma y otras identificadas con las iniciales T.A (Teodoro Aramburu), tratan sobre los actores y las compañías. En 1880 cambiará el subtítulo por Periódico satírico, alineándose con la causa republicana órgano de la izquierda liberal, con viñetas de Blas, algunas de ellas a doble página y tratando ya temas más sociales y de política local y nacional, como críticas a ciertas ordenanzas municipales y a Cánovas, prohibiéndose en numerosas ocasiones su publicación.
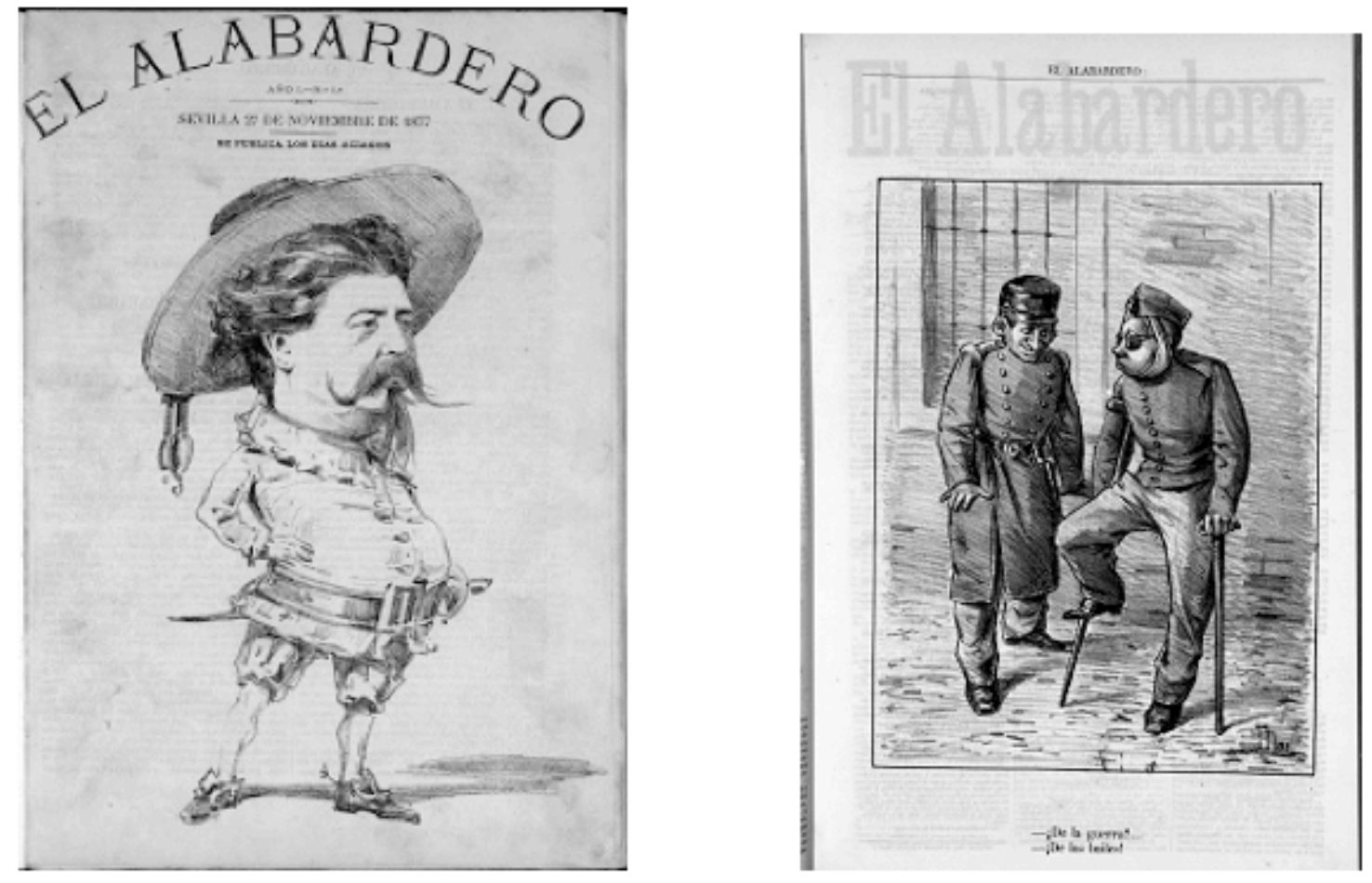

Imagen 13.- Portada N. 1 de El Alabardero. 27 de noviembre de 1877. En la segunda página ofrece en un pequeño verso un acertijo sobre el personaje de la portada:

Que hay notabilidades en Sevilla

Es cosa que sabemos al dedillo:

Hoy damos la primera maravilla...

Pún, catapún, chin, chin... ¡ Estebanillo!

Nosotros relacionamos a este Estebanillo con el personaje de la obra "La Vida y Hechos de Estebanillo Gónzález", novela picaresca del siglo XVII. El autor narra en su libro vivencias en la ciudad de Sevilla. 
Imagen 14.- Viñeta del dibujante Blas en El Alabardero el 10 de febrero de 1883. N. ․ 408. En ella observamos a dos soldados que charlan.

Texto: ¿De la guerra?... iDe los bailes!

De 1879 es La Cotorra, periódico satírico con caricaturas en la tercera página. Y La Caricatura, Revista ilustrada semanal, fundada en febrero de 1879, con dibujos de escaso mérito, que iban firmados con la inicial M, (ibíd, 1995: 223). De 1881 es El Látigo, periódico joco-serio con caricaturas.

iEl Pum! (1884), periódico Joco-serio y subtitulado Todo por Sevilla y para Sevilla, que pasaría a denominarse El Andaluz, publicación satírica, en 1885. Y la revista Juan Palomeque, personaje cari-feo, pancigordo, mani-zurdo y oji-breque cuya caricatura aparece en la portada del n. $\stackrel{1}{1}$ dibujada por Trucha.

En enero de 1886 nace El Baluarte, hasta 1906 (fue continuación de El Alabardero siguiendo con su numeración). Convirtiéndose ahora en un Diario político mercantil de cuatro páginas. El director era Juan Pérez Gironés y el más destacado de todos sus colaboradores José Rodríguez La Orden, alias Carrasquilla (Imagen 15), que desde su sección 'Murmuraciones' escribía en verso sátiras que reflejaban todos los aspectos de la vida nacional, en especial sobre los asuntos coloniales de Cuba y Filipinas, los resultados de la guerra, las negociaciones de la Paz con Norteamérica... Siendo: "el único elemento de la prensa sevillana de la época que, a nuestro juicio se identificaba con el sentir popular sobre el problema" (Sevilla Soler, 1986: 529).

Otra revista que alcanzó una notable popularidad por sus colaboradores fue Perecito (1887-1888), Periódico satírico literario. 

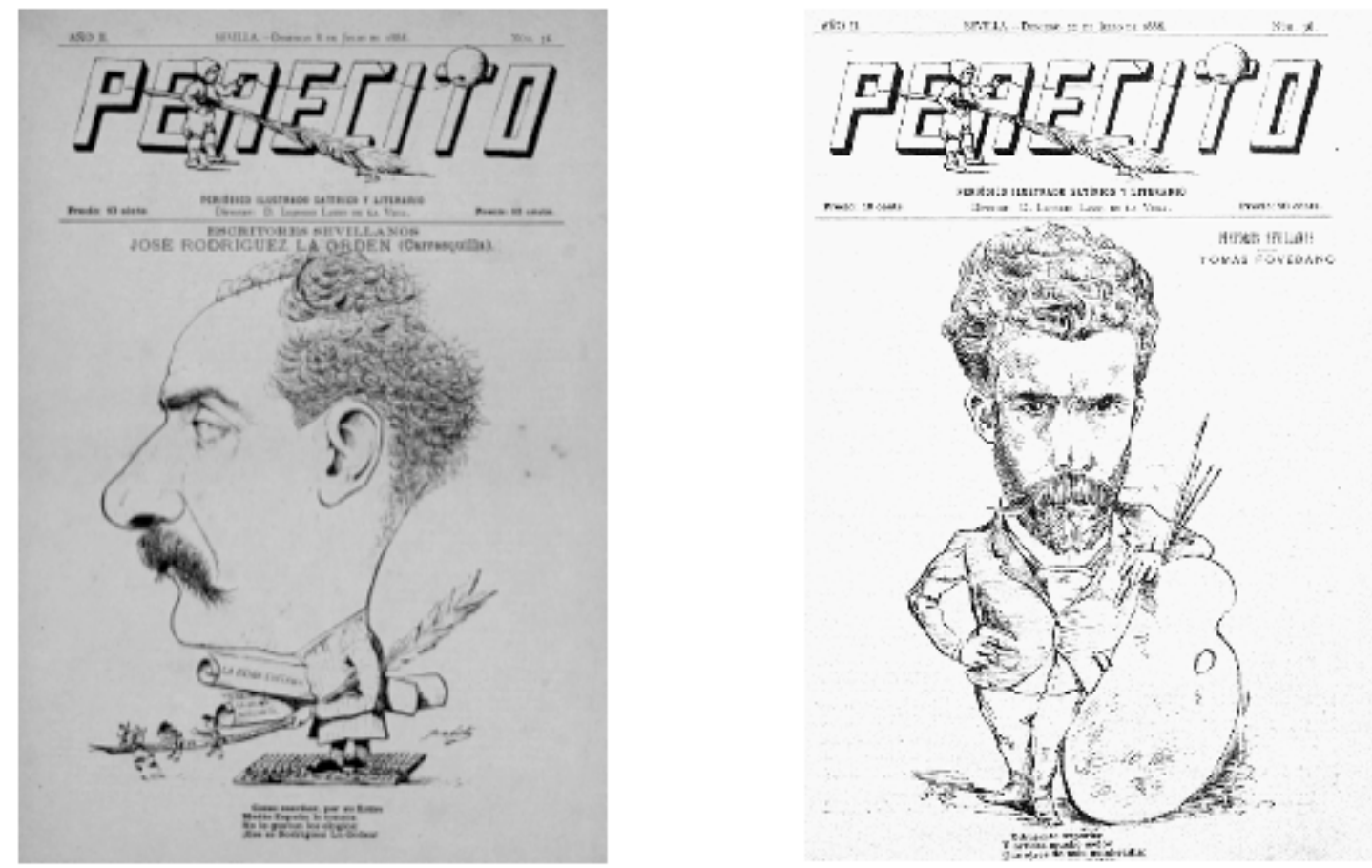

Imagen 15.- En el número 36 del 8 de julio de 1888 de la revista Perecito aparece una caricatura del escritor José Rodríguez La Orden (alias Carrasquilla) realizada por el dibujante Grafito.

Imagen 16.- Caricatura del dibujante y pintor Tomás Povedano por Grafito. Revista Perecito, n. ㅇ 38.22 de julio de 1888.

Obsérvese el modelo de caricaturas cabezones de cuerpos pequeñitos que pondría de moda Ramón Cilla en Madrid Cómico.

El director fue Leoncio Lasso de la Vega y luego Manuel Díaz Martín (dirigió también La Andalucía Moderna) y entre el staff de colaboradores estaban Serafín y Joaquín Álvarez Quintero ${ }^{34}$ (que entonces contaban 17 y 15 años de edad), Manuel Cano y Cueto, Luis Montoto, Benito Mas y Prat, Juan Antonio Torre (Micrófilo), Antonio Guerra Ojeda, Manuel Villena, Mercedes Velilla, Manuel Díaz Martín y José Sáinz Calvo. Además contó con los dibujantes Grafito (J. Moreno), Fefeneque (I. González), Alvarecito (Imagen 17), Tour, Alambrito y Tomás Povedano (Imagen 16), que realiza una historieta muda de seis viñetas en el n.․ 43, del 26 de agosto de 1888. Povedano fue pintor en la segunda mitad del siglo XIX. Retrató a Don Francisco Borja Palomo, Hermano Mayor de la Santa Caridad de Sevilla y catedrático de la Universidad de Sevilla (Valdivieso y Serrera, 1980: 100). También dibujó en El Alabardero, El Renacimiento (1884) y La Ilustración Bética (1881-1882), y realizó el cartel de la Feria de abril del año 1888 (Salas, 1991. Vol. II: 143).

En las portadas de Perecito aparecen caricaturas de personalidades de las artes y las letras y en su interior viñetas independientes del texto desde la Sección Historia

34 El 8 de enero de 1888 estrenaron su primera pieza teatral "Esgrima y Amor", de las doscientas veintiocho que llevarían a escena (ABC Sevilla, 30/1/1988. Pág. 14). 
Natural, comparando a personas con animales, verduras, siluetas y perfiles. En general era una revista festiva sin inmiscuirse en la política que trataba de ser simpática y entretener.

\section{PERECITO}

\section{A LAS SIETE DE LA TARDE}

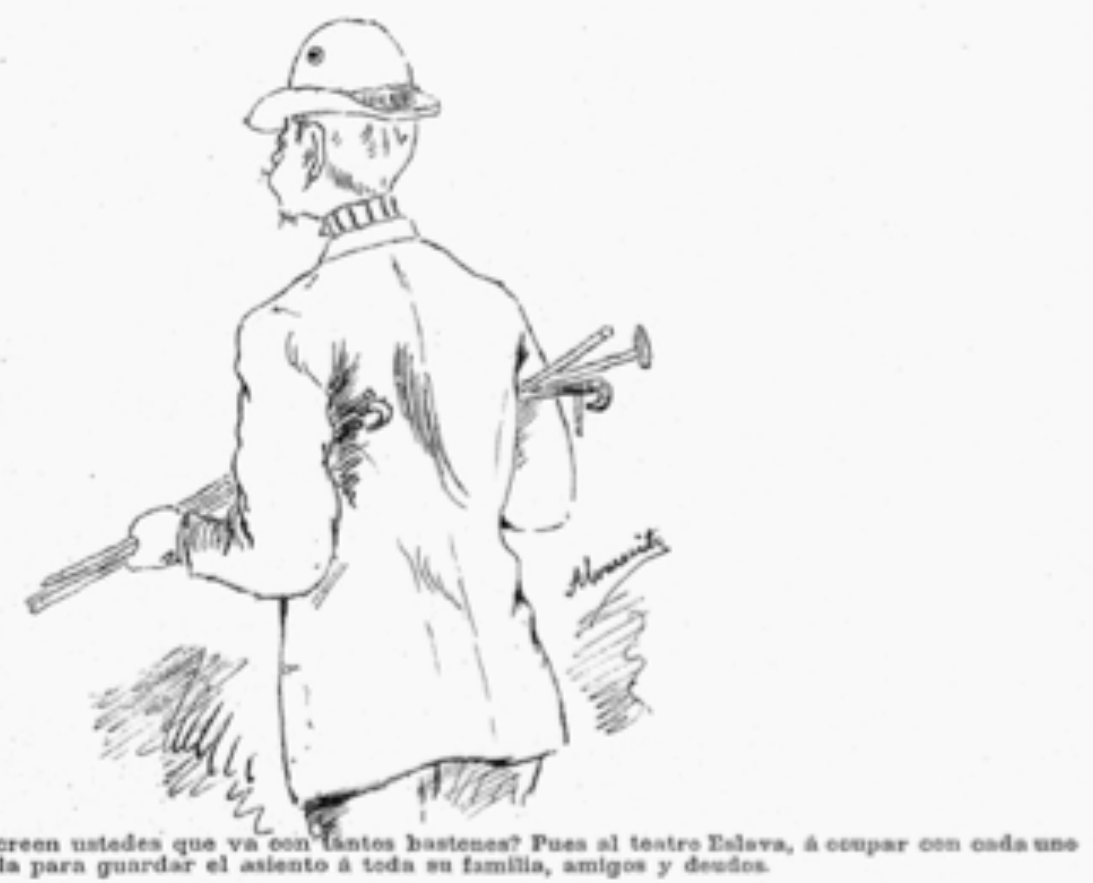

Imagen 17.- Perecito $\mathrm{n} . \mathrm{o} 41$ del 12 agosto de 1888. Viñeta firmada por Alvarecito, que podría pertenecer a los hermanos Álvarez Quintero atendiendo al diminutivo del apellido.

Texto: ¿Dónde creen que va con tantos bastones? Pues al teatro Eslava, a ocupar con cada uno de ellos una silla para guardar el asiento a toda la familia, amigos y deudos.

Uno de los dibujantes de Perecito, fue Grafito, que se corresponde con Juan Moreno Suárez ${ }^{35}$, que llegará a colaborar hasta en nueve publicaciones, en algunas de ellas como director. $\mathrm{Y}$ posiblemente sea también el autor de las obras firmadas con los seudónimos Frou-frou y Lambert.

Sus primeras colaboraciones escritas fueron en Tintinnabulum Hispalensis y EI Excomulgado (ambas de 1887), de carácter republicano. Y como dibujante, en EI Cometa, revista semanal literaria, donde ilustra la portada, la contraportada y las páginas centrales con textos a pie de dibujo hechos a mano. También dibujó J. Bermejo. Fue director de Los Gurripatos (1888), subtitulado Revista gurripaturesca, y EI

35 En la "Guía de Sevilla y su provincia", de 1888, p. 542, encontramos a Juan Moreno Suárez, de profesión delineante, que vivía en la calle Siete Revueltas, n. 13, de Sevilla, y en 1892 en c/Sol 16. Fue el autor del cartel de la Feria de abril de Sevilla de los años 1889 y 1893, este último junto con R. C. Candunets (Salas, 1991. Vol. II: 144). 
Bohemio, Periódico decenal humorístico, que sacó 3 números en enero de 1889, con dibujos sin firmar en la portada y en el interior. Estas revistas no las cita Chaves. $Y$ unos meses después aparece El Mosquito (Imagen 18), Periódico de Teatros, editando 8 números en 1889, con caricaturas de Grafito. El director fue Miguel Porcel y en su primer número podemos leer:

“El Mosquito saldrá por esas calles de Dios, una vez por semana, entrará en cafés, teatros, salones, asistirá a todos los espectáculos y zumbará lo mismo al oído de un cómico que al de un concejal ampuloso. Recorrerá la escala social y picará en las narices de cierta gentecilla menuda que tanto abundan en tantas partes".

Después, en junio de este mismo año, aparece Consolatrix y Aflictorum, también dirigida por Grafito. Revista semanal satírica ilustrada que editó también ocho números. En sus portadas aparecen caricaturas de tiples cómicas como Concepción Martínez (Imagen 19).
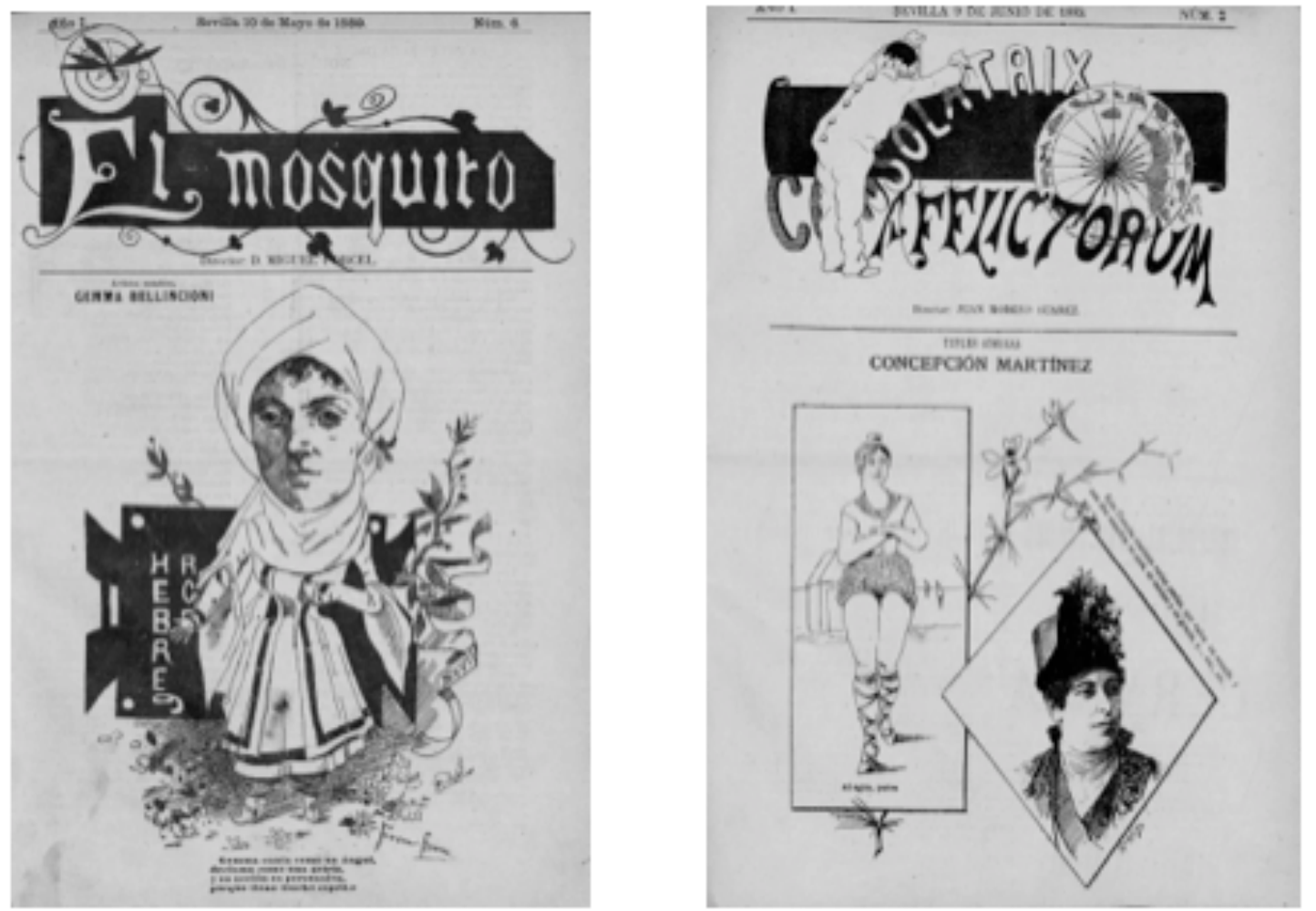

Imagen 18.-Portada de El Mosquito con caricatura realizada por Frou-frou (Grafito). Imagen 19.- Portada de Consolatrix y Aflictorum, dibujada por Grafito.

Sin duda, Grafito, llegó a tener su importancia en las revistas festivas de Sevilla, destacando en su vertiente de caricaturista siguiendo el estilo de R. Cilla de cabezones con cuerpecitos. Curiosamente, ambos llegaron a colaborar en Sevilla Cómica, (Imagen 20), que aparece en Sevilla el 3 de junio de 1888 y duró prácticamente medio año. 
Francisco Ramón de Cilla fue el director artístico durante los dos primeros números, cambiando después de titulares.
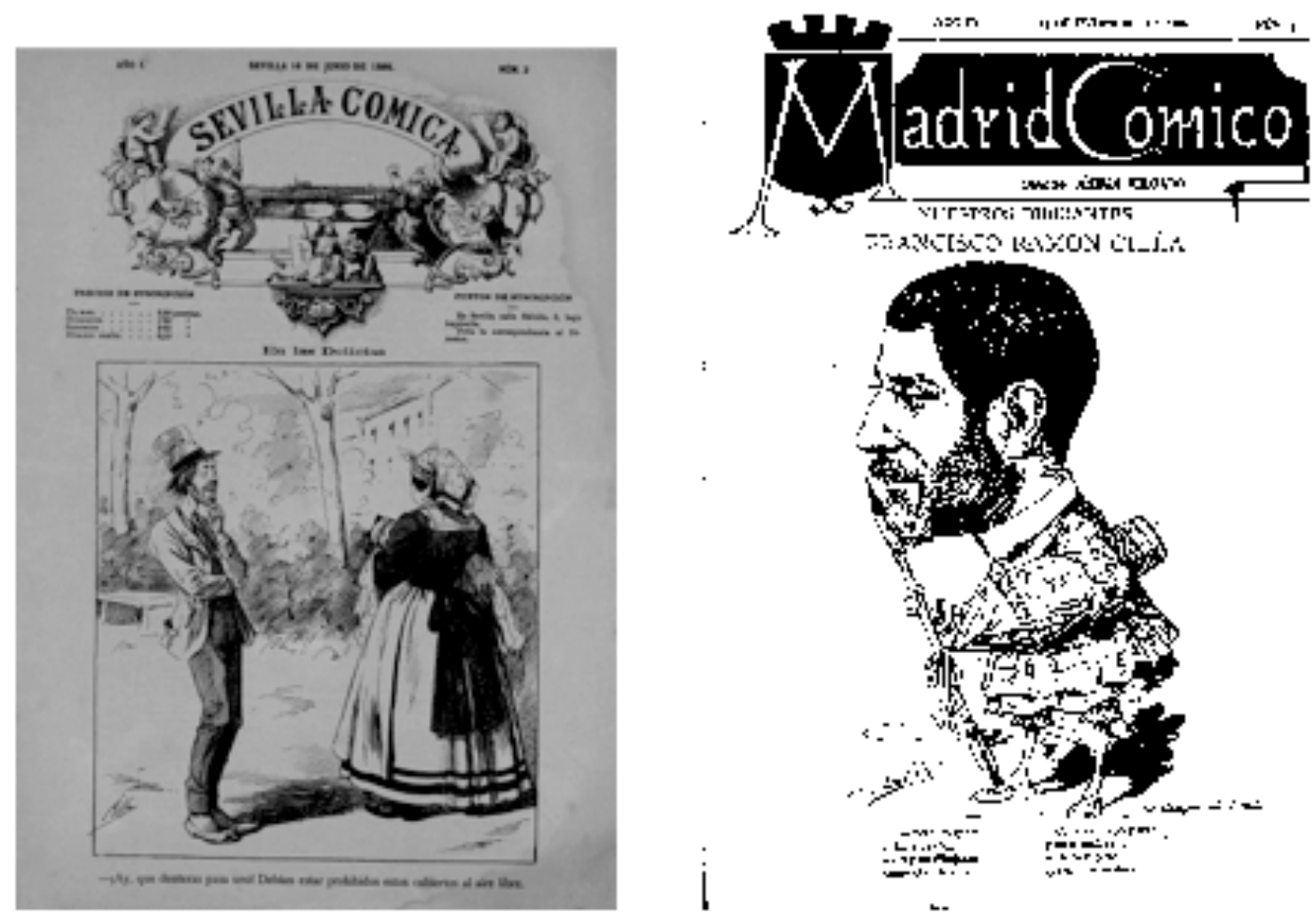

Imagen 20.- Portada de Sevilla Cómica n.o 2. 10 de junio de 1888. Con ilustración de Ramón Cilla. Imagen 21.- Portada de Madrid Cómico y caricatura de Ramón Cilla realizada por Mecachis. 23 de septiembre de 1883 . N. ㅇ 31 .

Fue ésta una prolongación de la madrileña Madrid Cómico (1880-1923), (Imagen 21), que: "extendía la fórmula de esta revista por otras ciudades de España con un formato similar, abriendo 'sucursales' en Santander, Granada, Sevilla, Valencia, Barcelona y La Coruña", (Barrero, M. 2011: 34). Y que ya gozaba de un importante prestigio. Prueba de ello es que el n. o 2 de Sevilla Cómica se agotó. Era considerada una revista de entretenimiento, festiva, donde la política es secundaria y donde escribían Mercedes de Velilla, Luis Montoto y Rautenstrauch, Benito Más y Prat, José Rodríguez La Orden, Eugenio Sedano, José Velilla, Manuel Cano y Cueto, Amante Laffón, entre otros.

A partir del n. o 3 dibujan Grafito, Frou Frou, J. Bermejo, José Fé y R. García, Zapirón, A. López y José $\mathrm{Arpa}^{36}$.

Las caricaturas de la portada retrataban a personajes de la ciudad y en el interior hay viñetas de costumbres de Sevilla y sus pueblos, "Imitando lo que ya había hecho

\footnotetext{
${ }^{36}$ José Arpa y Perea (Carmona 1860-1952). Uno de los grandes pintores sevillanos mejor cotizados. Colaboró en Sevilla Cómica después de una estancia de unos años en Roma (1883-1886) con una pensión de la Diputación de Sevilla. Vivió desde 1896 en México y San Antonio de Texas (EE. UU), durante más de 30 años. (Rodríguez, 2000: 546) y (Valdivieso, E. 1981: 124).
} 
Madrid Cómico" (Ibíd, 1995: 290). Trata temas como la caída del cimborrio de la catedral en el verano de 1888 y el asesinato de la calle Fuencarral de Madrid, caso que llegó a ser muy popular, y comentarios sobre el alcalde de Sevilla, Francisco Varea y Torrealba. También sobre las tertulias de la Plaza Nueva y del bar Eslava.

Diez años después, en septiembre de 1898 volvería a reeditarse Sevilla Cómica con caricaturas en la portada realizadas por Atchits y dibujos en el interior de Morbo. Tras cuatro números en la calle anuncia que se transformará en la revista Equis, semanario satírico dedicado a la literatura, las artes y espectáculos.

Otras revistas serían El Buen Humor de 1890. Semanario satírico ilustrado, sacando 7 números en 1890, con dibujos de K-ceres (Luis Cáceres), en la portada, páginas centrales y la última. El director era José Manuel Villena y uno de sus colaboradores Ricardo Parody.

En 1893 encontramos a La Tarántula, Juan Palomo y Sevilla en Broma, ésta última de ocho páginas en blanco y negro que llegó a editar 16 números. Era una publicación festiva dirigida por Fernando Trigo y cuya cabecera diseñó J. Arpa. En las portadas aparecen caricaturas de Fernando Tirado, cuyos originales estaban realizados al óleo, según los apuntes del bibliófilo José Gestoso. En ellas retrata o aparecen caricaturados (expresión que utiliza la revista), personajes sevillanos ${ }^{37}$ de las letras, artes, la política, la docencia y la arqueología. En las páginas centrales del primer número dibujaron Teodoro Aramburu y su hermano Ricardo. Después aparecen historietas y viñetas lámina de Pinto, Nicolás Pineda, Luis Cáceres, Wisse y A. P. Cides.

Con un título parecido nace en 1894 Serio y Broma, y de la que salieron solo seis números, con dibujos de J. Moyano, G. Díaz Infante y R. Cilla y fotograbados de Chalosan y Thomás. También Campanone, revista de espectáculos con viñetas intercaladas y dibujos en fotograbado en la portada. Y de 1895 El Giraldillo. Periódico satírico de literatura, Artes, Espectáculos y de Intereses morales y materiales, con viñetas y grabados.

Juan del Pueblo (1895), se subtitulaba Periódico satírico con muñecos y caricaturas y con más púas que un erizo y más agallas que una corvina. Sacó 9 números con unas tiras cómicas-mudas de cuatro viñetas en vertical. $Y$ sátiras en prosa desde las secciones Banderillas, Marronazos y Golletazos. Al parecer, Juan de Pueblo surge en el diario El Tribuno de 1884, por el señor Barbado (Ibíd, 1995: 263). El 18 de abril de 1896 nace Mari Clara, subtitulada Revista festiva ilustrada. Se publica cada ocho días si el tiempo lo permite. Se editaron cuatro números y dibujan Rafael Santa Ana (que

37 En las 16 portadas de Sevilla en Broma aparecen consecutivamente: Manuel Cano y Cueto, Juan Sánchez Lozano, Juan Romea, Felipe Pérez González, Carlos María Santigosa, Gonzalo Bilbao, José Gestoso, Luis Montoto, Juan Moreno, J. M. de Hoyos, Francisco Narbona, Antonio María Ariza, José María Gutiérrez de Alba, Javier Sánchez Dalp y José Lafita y Blanco. 
posiblemente usaba los seudónimos de San y Chalosan), Luis Cáceres, Andrés Cánovas y J. Funes, con una historieta a doble página sobre La Caza del oso.

Piave (1898), Semanario satírico sin pretensiones. Se presenta como: "El amigo íntimo, el confidente del ilustre Gedeón (revista satírica madrileña), que viene a decir sandeces, ni más ni menos que cualquier individuo de los que tienen asiento en las cámaras, en las Academias y Ateneos". En la portada sale una caricatura retrato del diputado provincial Manuel Fernández Santa Cruz.

Nombramos también a Gran Cónclave, aunque es un manuscrito original del que solo conocemos los dos primeros números de septiembre de 1898 (posiblemente para pasar a imprenta). En él participa escribiendo y dibujando G. F. Tovar, autor 20 premio del cartel de la Feria de abril de 1914 (Salas, 1991. Vol. II: 144), con la obra "Concha".

Y terminamos esta recopilación citando a La Fusta (1887 y 1902) y (1911-1924), y Don Cecilio de Triana (1899-1922), dirigida por José María García Rufino e ilustrada por Manolo. Siendo éstas dos últimas revistas del siglo XIX las que perdurarán hasta bien entrado el siglo XX.

\section{Conclusiones}

1 La gran dificultad de elaborar esta recopilación de publicaciones satíricas sevillanas ha sido la de localizar dichas cabeceras, que en muchos casos ya están desaparecidas y solo tenemos la certeza de ellas gracias a las obras bibliográficas citadas al comienzo del artículo. No obstante, muchas de ellas se encuentran en bibliotecas, hemerotecas e instituciones afines y gracias a donaciones de algunos bibliófilos del siglo XIX, como Joaquín Hazañas, José Gestoso, Luis Montoto, Guichot, Collantes de Terán, el duque de T' Serclaes y su hermano el marqués de Jerez de los Caballeros, José Vázquez y Ruiz, Gómez Imaz, etc.

2 El siglo XIX es considerado como la edad de oro de las revistas satíricas y los caricaturistas. Gracias a estas publicaciones se comprenden mucho mejor los acontecimientos transcendentales de la Historia de España en general y Sevilla en particular, debido a la estrecha relación que había (y hay) entre la ilustración gráfica y la realidad político social y cultural de cada momento: "Si hay en el arte un aspecto que camina paralelo a la Historia y muchas veces la adelanta, la modifica, influye sobre ella, moldeándola a su antojo... ese aspecto es la caricatura" (Francés, 1915: 9).

3 En este sentido, la caricatura y las viñetas han sido la imagen del siglo XIX, siendo un arma de doble filo, ya que han servido para criticar sucesos políticos y a sus protagonistas desde las publicaciones satíricas políticas y para homenajear y dar a conocer a ciertas personalidades, sobretodo desde las portadas de las revistas festivas. $\mathrm{Y}$ en la propia necesidad de transmitir más, la caricatura del siglo diecinueve; 
recargada, asimétrica y que exageraba los rasgos físicos, evolucionará en el siglo XX hacia la caricatura de línea simple y con economía de trazos, más interesada en reflejar con siluetas el interior de la persona, su psicología y pensamiento, como las realizadas, entre otros, por el dibujante Luis Bagaría (Barcelona, 1882-La Habana, 1940), (Elorza, 1988).

\section{Referencias bibliográficas}

ARCAS CUBERO, Fernando (1990): El País de la Olla. La imagen de España en la prensa satírica. Málaga. Editorial Arguval.

ARIAS CASTAÑÓN; E. (2009): Ideología y Política en Sevilla bajo la Monarquía de Amadeo de Saboya. Sevilla. Diputación de Sevilla. Área de Cultura e Identidad. Servicio de Archivo y Publicaciones.

ARIAS CASTAÑóN; E. (2010): La Revolución de 1868 en Sevilla. Ayuntamiento de Sevilla, ICAS.

BARRERO MARTínEZ, Manuel (2011): “Orígenes de la Historieta Española, 1857-1906". La historieta española, 1857-2010. Historia, sociología y estética de la narrativa gráfica en España. A. Altarriba (coord.) ARBOR. Ciencia, Pensamiento y Cultura. Vol. 187, p.15-42. CLXXXVII, 2Extra. 2011. CSIC.

BARRERO MARTíNEZ, Manuel (2015): TD. Sistemática de la Historieta. Aplicación al caso de la Historieta y el Humor Gráfico en Sevilla: 1864-2000. Facultad de Comunicación. Departamento Comunicación, Publicidad y Literatura. Universidad de Sevilla.

BAUDELAIRE, Charles (2015): Lo Cómico y la Caricatura y El Pintor y la vida moderna. Introducción de Valeriano Bozal. Colección La Balsa de la Medusa, 203. Madrid. Antonio Machado Libros.

BOZAL, V. (1989): "El siglo de los caricaturistas". Madrid. Historia 16. N. 40.

BRAOJOS, A. PARIAS, M. a y ÁLVAREZ, L. (1990): Historia de Sevilla. Sevilla en el siglo XX. (1868-1950). Tomo: I. Secretariado de Publicaciones de la Universidad de Sevilla.

BURKE, Peter (2001): Visto y no visto. El uso de la imagen como documento histórico. Barcelona. Crítica.

CAPARRÓS MASEGOSA, Lola y GAMONAL TORRES, M. A. (2010): “Gedeón en las Exposiciones Nacionales de Bellas Artes (1897-1912)". Crítica de arte y caricatura 
política en la España de la Restauración. Revista "Cuadernos de Arte", Universidad de Granada. Vol. 41, pp. 249-268.

CAPELLÁN DE MIGUEL, G. (2010): “La Opinión Secuestrada. Prensa y Opinión Pública en el siglo XIX". BERCEO. Revista Riojana de Ciencias Sociales y Humanidades. N.으 159 , pp. 23-62.

CASADO CIMIANO, Pedro (2006): Diccionario biográfico de ilustradores españoles del siglo XIX. Madrid. Ollero y Ramos, editores.

CASCALES MUÑOZ, J. (1929): Las Bellas Artes en Sevilla. La pintura, la escultura y la cerámica artística desde el siglo XIII hasta nuestros días. Tomo I.

CHAVES, M. (1904): Noticia periodística del pintor D. José Chaves y Ortiz. Prólogo de Luis Montoto. Sevilla. En "Biografías y necrologías", Varios autores. Sevilla, 18801917.

CHECA GODOY, A. (2016): "Auge y crisis de la prensa satírica española en el Sexenio Revolucionario (1868-1874)". El Argonauta Español, Revue bilingue, francoespagnole consacrée à l'étude de la presse espagnole de ses origines à nos jours (XVII ${ }^{\circ} X X I^{\circ}$ siècles), $\mathrm{n}^{\circ} 13$. http://argonauta.imageson.org/document97html

COMELLAS, J. L. (1977): La Restauración como Experiencia histórica. Sevilla. Secretariado de Publicaciones de la Universidad de Sevilla.

CONDE, L. (2002): Historia del Humor Gráfico en España. Lleida. Editorial Milenio. Lleida.

CUENCA TORIBIO, M. (1991): Historia de Sevilla. Del Antiguo al Nuevo Régimen. Secretariado de Publicaciones de la Universidad de Sevilla. Sevilla, 4a Edición.

ELORZA, Antonio (1988): Luis Bagaría. El humor y la política. Barcelona. Anthropos.

FRANCÉS, J. (1915): La caricatura contemporánea española. Madrid. Imprenta J. Pueyo.

GAMONAL TORRES, M. A. (1983): La llustración gráfica y la caricatura en la prensa granadina del siglo XIX. Diputación Provincial de Granada.

GARCÍA QUIRÓS, Rosa M.a (1985): "Política y caricatura. El desastre colonial español a los ojos de los humoristas gráficos (1895-1898)". Liño. Revista Anual de Historia del Arte. ‥ 5 . Universidad de Oviedo.

GARRIDO CONDE, M. a T. (1999): TD. La Prensa satírica en Sevilla durante el s. XIX. Estudio monográfico del periódico El Clarín. U. Complutense de Madrid. 
GIL JIMÉNEZ, M. a Dolores (1977): La Ilustración Bética. Sevilla 1881-1882. Diputación de Sevilla.

GUICHOT y Sierra, Alejandro (1897): Notas Bibliográficas de las obras literarias y gráficas de Don Joaquín Guichot.

GUTIÉRREZ JIMÉNEZ, M.a Eugenia (2016): TD. Del romance vulgar a la prensa de masas: El dibujo satírico en la prensa sevillana. Los modos de ver El Tío Clarín (1864-1871). Universidad de Sevilla.

LLERA RUIZ, J. A. (2003): "Una historia abreviada de la prensa satírica en España: desde El Duende Crítico de Madrid hasta Gedeón". Revista Estudios sobre el mensaje periodístico, Vol. 9, pp. 203-214. U. Complutense de Madrid.

MARTín, A. (1978): Historia del Cómic español: 1875-1939. Barcelona. Gustavo Gili.

MELÉNDEZ Malavé, N. (2007): "Los inicios de la Prensa Satírica en Andalucía". Revista Andalucía en la Historia, año V, N. ำ15, pp. 62-68.

MÉNDEZ Paguillo, J. C. (2017): "Manolo, dibujante de la revista Don Cecilio de Triana", 2017. J. Carlos Méndez Paguillo. Ámbitos de la Comunicación. Edición de primavera. Universidad de Sevilla. N. o 36.

PONS RODRÍGUEZ, Lola (2000): “La escritura 'en andaluz' en tres periódicos del XIX: El Tío Tremenda $(1814,1823)$, El Anti-Tremenda (1820) y El Tío Clarín (1864-1871)”. Philologia Hispalensis, Vol. 14, N. 1, pp. 77-98.

OSSORIO BERNARD, M. (1975): Galería biográfica de artistas españoles del siglo XIX. Madrid, reedición de 1868 .

OTERO Fernández, Mercedes. (2004): La política gaditana y jerezana en la prensa satírica. 1874-1923. Servicio de Publicaciones de la Universidad de Cádiz.

REIG, Ramón y RUIZ ACOSTA M.a J. (1998): Sevilla y su Prensa: Aproximación a la Historia del Periodismo andaluz contemporáneo (1898-1998), Sevilla, Ámbitos de la Comunicación I. Grupo de Investigación en Estructura, Historia y Contenidos de la Comunicación. Universidad de Sevilla.

RODRÍGUEZ AGUILAR, I. C. (2000): Arte y Cultura en la Prensa. La pintura sevillana 1900-1936. Secretariado de publicaciones de la Universidad de Sevilla.

RUIZ DÁVILA, R. (2012): “Breve aproximación a la historieta andaluza" Revista Atrio, 18 (2012), pp. 95-105. ISSN: 0214-8289.

SALAS, Nicolás (1991): Sevilla. Crónicas del siglo XX. Tomo I y II. Secretariado de Publicaciones de la Universidad de Sevilla. 
SEVILLA SOLER, M. a , Rosario (1986): "La Crisis del 98 y la sátira en la prensa sevillana", en Andalucía y América en el siglo XIX. Actas de las $\mathrm{V}$ jornadas Andalucía y América. Universidad Santa María de la Rábida, pp. 507-540.

SUMMA ARTIS. Tomo XXXII. El Grabado en España (siglos XIX-XX). F. Fontbona. Madrid, 1988.

VALDIVIESO, E y SERRERA, J. M. (1980): El Hospital de la Caridad de Sevilla. Sevilla.

VALDIVIESO, E. (1981): Pintura sevillana del siglo XIX. (Autor-editor). Impreso en los talleres de la Editorial Server-Cuesta. Sevilla. (I.S.B.N. 84-300-6127-4).

VILLALBA DÍAZ DE MAYORGA, S. (1991): "José Chaves, pintor de escenas taurinas". Revista de Historia del Arte, ISSN 0214-8293, N. o 3, pp. 175-188. 